\title{
Functional and genetic interactions of TOR in the budding yeast Saccharomyces cerevisiae with myosin type II-deficiency (myo1 $\Delta$ )
}

\author{
Glorivee Pagán-Mercado, Ednalise Santiago-Cartagena, Pearl Akamine and José R Rodríguez-Medina*
}

\begin{abstract}
Background: Yeast has numerous mechanisms to survive stress. Deletion of myosin type II (myol $\Delta$ ) in Saccharomyces cerevisiae results in a cell that has defective cytokinesis. To survive this genetically induced stress, this budding yeast up regulates the PKC1 cell wall integrity pathway (CWIP). More recently, our work indicated that TOR, another stress signaling pathway, was down regulated in myo $1 \Delta$ strains. Since negative signaling by TOR is known to regulate $P K C 1$, our objectives in this study were to understand the cross-talk between the TOR and PKC1 signaling pathways and to determine if they share upstream regulators for mounting the stress response in myo $1 \Delta$ strains.
\end{abstract}

Results: Here we proved that TORC1 signaling was down regulated in the myol $\Delta$ strain. While a tori $\Delta$ mutant strain had increased viability relative to myo $1 \Delta$, a combined myol $\Delta$ tor $1 \Delta$ mutant strain showed significantly reduced cell viability. Synthetic rescue of the tor $2-27^{t s}$ lethal phenotype was observed in the myo $1 \Delta$ strain in contrast to the chs $2 \Delta$ strain, a chitin synthase II null mutant that also activates the PKC1 CWIP and exhibits cytokinesis defects very similar to myo1 $\Delta$, where the rescue effect was not observed. We observed two pools of Slt2p, the final Mitogen Activated Protein Kinase (MAPK) of the PKC1 CWIP; one pool that is up regulated by heat shock and one that is up regulated by the myol $\Delta$ stress. The cell wall stress sensor WSC1 that activates PKC1 CWIP under other stress conditions was shown to act as a negative regulator of TORC1 in the myo1 $\triangle$ mutant. Finally, the repression of TORC1 was inversely correlated with the activation of $P K C 1$ in the myol $1 \Delta$ strain.

Conclusions: Regulated expression of TOR1 was important in the activation of the PKC1 CWIP in a myo1 $\Delta$ strain and hence its survival. We found evidence that the PKC1 and TORC1 pathways share a common upstream regulator associated with the cell wall stress sensor WSC1. Surprisingly, essential TORC2 functions were not required in the myol $\Delta$ strain. By understanding how yeast mounts a concerted stress response, one can further design pharmacological cocktails to undermine their ability to adapt and to survive.

Keywords: PKC1, SLT2MPK1, WSC1, Tor2-21, Fungal cell wall

\section{Background}

The calcium-dependent protein kinase (Pkc1p) and target-of-rapamycin (TOR) signaling pathways are conserved in yeast and other fungi and are important for stress response and fungal survival. In addition to regulating growth and metabolic activity in normal cells, these pathways also regulate the cellular response to

\footnotetext{
*Correspondence: jose.rodriguez123@upr.edu

Department of Biochemistry, School of Medicine, Medical Sciences Campus, University of Puerto Rico, PO Box 365067, San Juan, PR 00936-5067, USA
}

transient cell wall stress during the normal yeast life cycle, and during exposure to heat shock, cell wall damage, or other stressors that can compromise cellular integrity [1-3]. Our studies with myosin type II-deficient (myo14) strains of the budding yeast Saccharomyces cerevisiae, which we have characterized previously as stress mutants, showed that the Pkclp pathway is activated and essential for myo1 $\Delta$ strain survival [4-6]. It has been our contention that this activation is due to cell wall stress caused by morphological abnormalities in the lateral cell wall and bud neck architecture $[7,8]$. In 
response to cell wall damage, heat shock, and other types of environmental stress, Rholp activates the PKC1 cell wall integrity pathway (CWIP), which in turn activates Slt2p (Mpk1p), the Serine/Threonine (Ser/Thr) MAPK at the end of this cascade [1-3]. This leads to transcriptional up regulation of cell wall-related genes by the Rlm1p transcription factor [9-12]. In addition to regulating the genetic program for cell wall integrity through the transcription factor Rlm1p $[9,13,14]$, Slt2p may also modulate $P K C 1$ activity indirectly by a previously proposed feedback mechanism that phosphorylates and down regulates the Rho1p GDP-GTP Exchange Factor (GEF) Rom2p [15]. Rho1p also functions as the regulatory subunit of Fks1p, a $\beta-1,3$-glucan synthase for lateral cell wall fortification [16].

In prior studies, we have shown that similar to wildtype (wt) cells under stress conditions, the myo1s mutant (a genetically induced stress caused by the deletion of myosin II heavy chain that inhibits normal cytokinetic ring assembly) also activates the PKC1 CWIP, but uses a different repertoire of genes [4,5]. Further characterization of the genes of the myo1s mutant at the post-transcriptional level showed that only a subset of cell wall integrity genes was activated. Thus, the myol $\Delta$ mutant may serve as a simplified model for studying the cell wall stress response. Furthermore, we found that translation and ribosome biogenesis were down regulated in the myo1 $\Delta$ strain [17]. This observation led us to investigate the role of TOR in the myold strain survival and how it may complement the reduced CWIP response.

Yeast TOR consists of two proteins - Tor1p and Tor2p - which are contained in two protein complexes TORC1 and TORC2 $[18,19]$. The TORC1 complex that is sensitive to rapamycin treatment contains proteins Tor1p or Tor2p, Kog1p, Tco89p and Lst8p [18,20-22]. TORC2 that is resistant to rapamycin treatment contains Tor2p, Avo1p, Avo2p, Avo3p, Bit61p, and Lst8p [18,20]. Recent subcellular localization studies showed that Tor1p was concentrated near to the vacuolar membrane while Tor $2 p$ was predominantly in punctuate structures near to the cytoplasmic surface of the plasma membrane [23]. Their differences in composition, sensitivity to rapamycin, and cellular localization support the idea that they function as two separate complexes $[18,20,23]$. TOR is important for nutrient sensing and is believed to play an important role in life span extension [24-27]. While TOR is conserved structurally and functionally

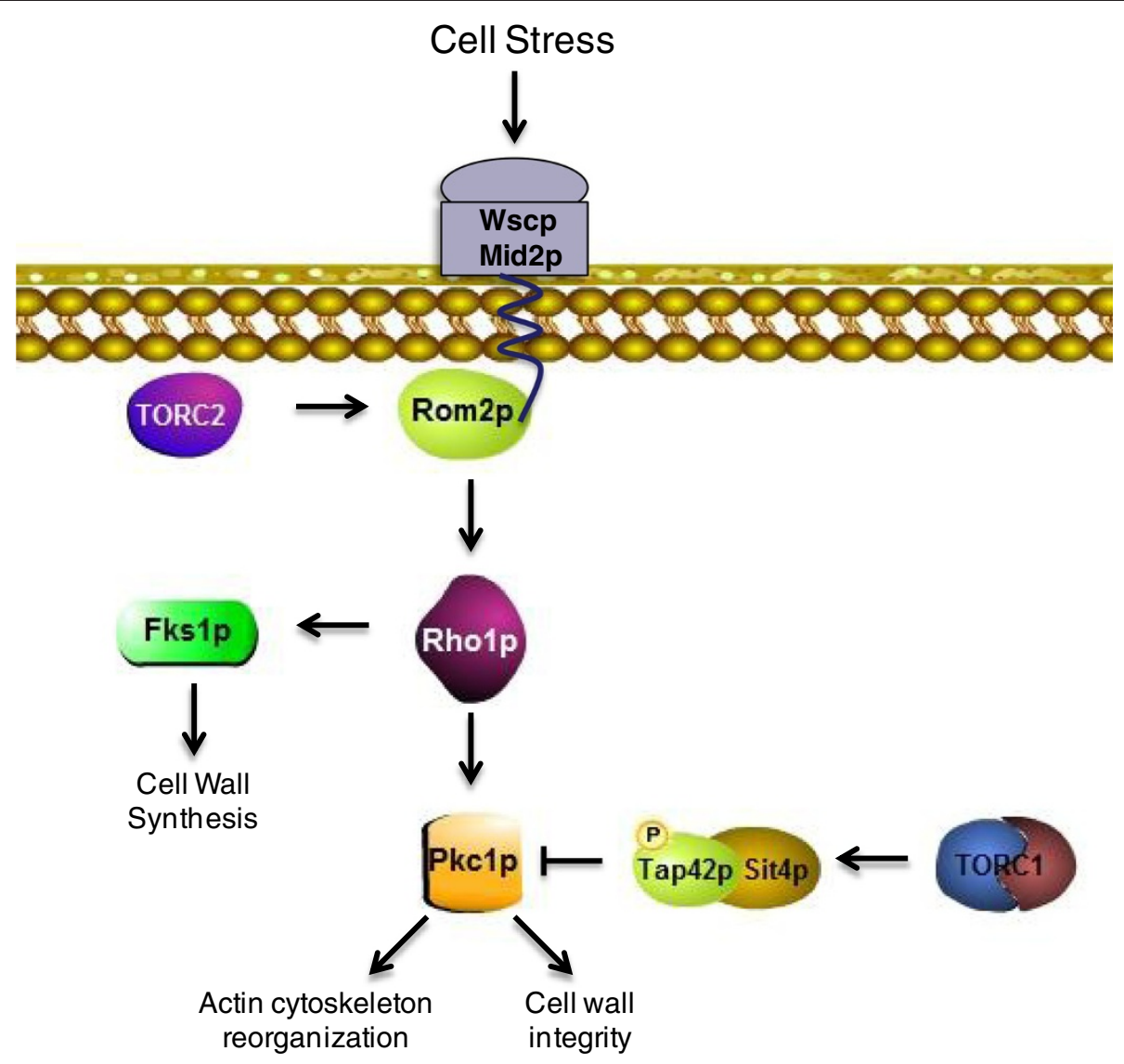

Figure 1 General Description of the known interactions between the PKC1-Cell Wall Integrity and TOR Pathways in budding yeast. 
from yeast to human, their roles are not biologically identical and warrant careful characterization of TOR from both species.

Rho1p is regulated by two mechanisms, a TORindependent mechanism that is activated by cell wall stress (discussed above) and a separate TORC2dependent mechanism that regulates actin cytoskeleton reorganization through the Rholp-dependent activation of PKC1 [28]. In this latter pathway, Rom2p activity is indirectly modulated by the essential phosphatidylinositol kinase TORC2 via a GTPase switch consisting of Rho1p, Rho2p, Rom2p, and Sac7p (a GTPase activating protein of Rho1p) [29,30]. In short, the TORC2dependent association of Rho1p (and Rho2p) with the Rom2p phosphatidylinositol-binding domain promotes Rom2p activation and downstream events [30,31]. In this manner Rom $2 p$ functions as the relay by which TORC2 regulates polarization of the actin cytoskeleton via Pkc1p. Therefore, functional interconnections between Pkc1p and TORC2 have been proposed through a mechanism integrated by the Rho1p-Rom $2 p$ complex [30,31] (Figure 1).

The stress sensor proteins Wsc1p, Wsc2p, Wsc3p, Mid2p and Mtl1p are involved in the activation of cell integrity signaling [2,32-37]. These cell surface sensors span the plasma membrane and are attached to the extracellular cell wall. The Mid2p homologue Mtl1p, that shares $50 \%$ sequence identity with Mid2p, appears to have a minor role in $P K C 1$ signaling [14]. These sensors react differently under specific stress conditions [37]. It has been reported that cells lacking WSC1 are hypersensitive to drugs interfering with the cell wall and plasma membrane like Calcofluor white, Congo red, Caspofungin, Chlorpromazine and tea tree oil [1,38-40]. Additionally, Wsclp responds to hypo-osmotic and alkaline $\mathrm{pH}$ conditions $[39,41]$. A mid $2 \Delta$ mutant is hypersensitive to pheromone treatment, is hyperresistant to Calcofluor white, tea tree oil and Congo Red, and it senses acidic conditions and vanadate [32,37,39,40,4244]. Wsc1p and Mid2p are also involved in the response to heat shock $[2,33,35,45]$. WSC2 and WSC3 act as suppressors of mutants defective in glycerol synthesis [37], while Mtllp is associated with response to oxidative stress and glucose starvation $[46,47]$. The Wsc family of proteins and Mid2p have been shown to interact with specific signaling proteins that transmit stress signals from the fungal cell wall sensors to the Pkclp and TOR signaling pathways. For example, Rom2p, the GEF that regulates Pkc1p, physically interacts with Wsc1p, Wsc2p, and Mid2p to activate the PKC1 CWIP in the response to cell wall stress $[36,48,49]$. To define the nature of these signaling interactions in myo1 $\Delta$ strains, we demonstrate here that TORC1 and Pkc1p activities were inversely correlated, which suggests cross-talk between the two pathways. Furthermore, we found that TORC1 was down regulated in myo1 $1 \Delta$ strains by a mechanism that required expression of Wsc1p but not the other cell wall stress sensors. Surprisingly, Tor2p functions were not essential for survival in myo1 $\Delta$ cells.

\section{Results}

TORC1 activity is down regulated in myo1 $1 \Delta$ strains

To test the hypothesis that the TORC1 pathway was down regulated in the myol $\Delta$ strain, we measured the levels of phosphorylated or dephosphorylated Npr1p to assess the TORC1 status [50]. TORC1 signaling regulates phosphorylation of the Ser/Thr protein kinase Npr1p at 22 potential phosphorylation sites [51,52]. At steady state, Nprlp is maintained inactive by phosphorylation [51] (Figure 2A, left diagram). Inhibition of TORC1 activity by nutrient starvation or application of the antiproliferative drug rapamycin results in dephosphorylation and subsequent activation of Npr1p by the protein phosphatase Sit4p [50,51,53] (Figure 2A, right diagram). To detect Npr1p in the myo1 $\Delta$ strains, an expression plasmid containing a functional $\mathrm{N}$-terminal hemagglutinin (HA)-tagged NPR1 gene (HA-NPR1) was transformed into wt and mutant strains [54].

The phosphorylation state of Nprlp can be deduced from its relative electrophoretic mobility on SDSpolyacrylamide gel electrophoresis (SDS-PAGE) and detected by Western blot analysis using an anti-HA antibody. In wt whole cell extracts, Npr1p was detected as a slower-migrating band, which corresponds to the hyperphosphorylated form, $\mathrm{Npr}^{\mathrm{P}} \mathrm{p}^{\mathrm{P}}$ (Figure $2 \mathrm{~B}$, lane 1). Treatment of wt whole cell extracts with exogenous Calf Intestinal Alkaline Phosphatase (PPase) converted the slower-migrating band to a faster-migrating band which corresponds to the in vitro dephosphorylated form, Npr1p (Figure 2B, lane 2). Treatment of wt cell cultures with rapamycin produced a faster-migrating Npr1p band that co-migrated with the PPase treated band, consistent with the inhibition of TORC1 activity by rapamycin (Figure 2B, lane 3). This experiment established that the activity of TORC1 could be assessed indirectly by observing the relative electrophoretic mobility of Npr1p by SDS-PAGE [50,53].

In myo1s whole cell extracts, no change in the electrophoretic mobility of Npr1p was observed as judged by the co-migration of Nprlp bands in extracts from rapamycin treated and untreated cells (Figure $2 \mathrm{C}$, lanes 1 and 3). This result suggested that Npr1p is dephosphorylated at steady state in the myo1 $\Delta$ strain. A chs $2 \Delta$ strain (a chitin synthase II null mutant defective in contractile ring function) and an $f k s 1 \Delta$ strain (a $\beta$-1,3-glucan synthase null mutant deficient in cell wall synthesis and maintenance) were incorporated as controls representing strains under cell wall stress $[55,56]$. In contrast, the 


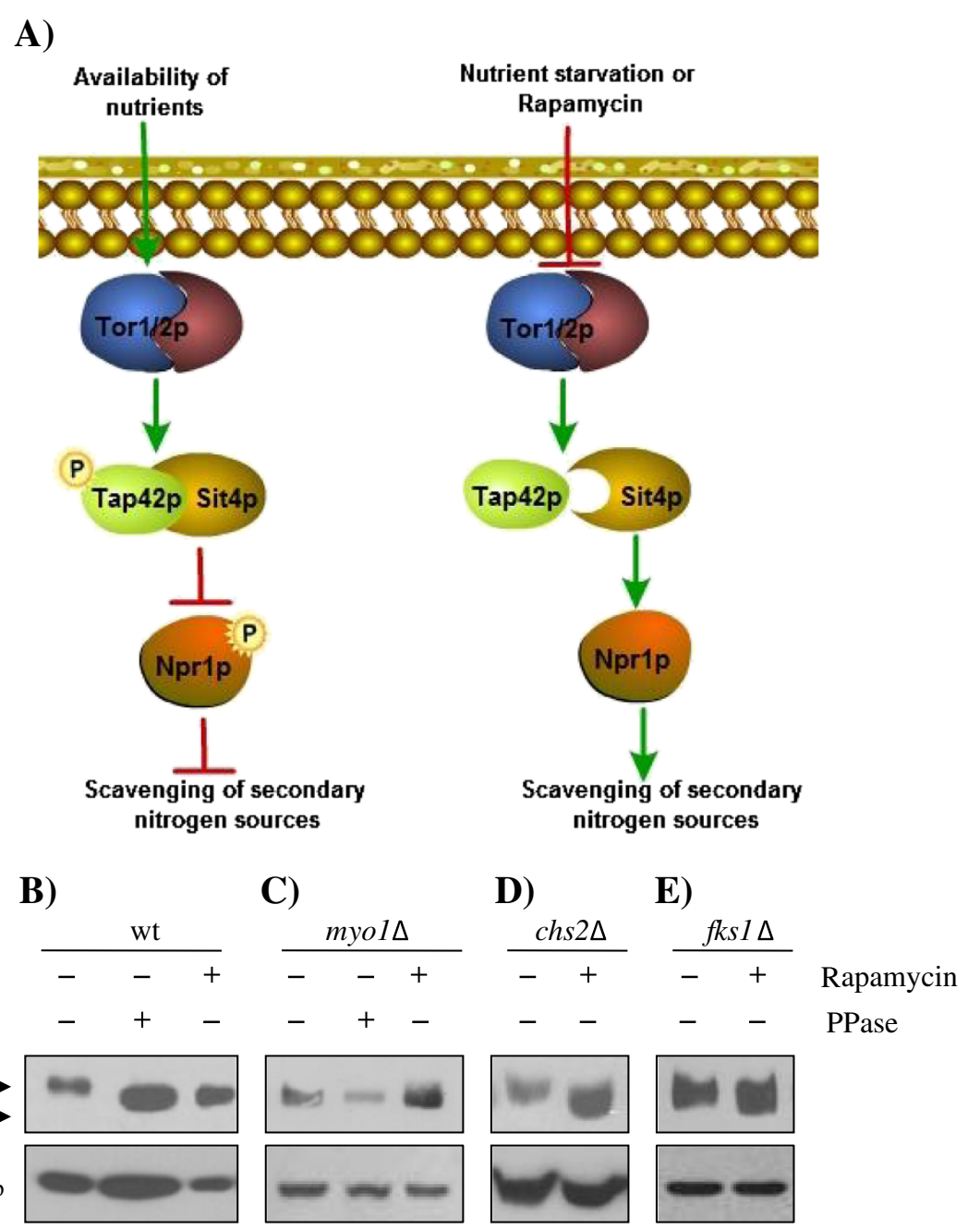

Figure 2 The TORC1 pathway is down regulated in myo1 strains but not in other cell wall stress models. A) Schematic representation of the TOR signaling pathway and regulation of the phosphorylation state of Npr1p following inhibition of TOR by nutrient starvation or rapamycin. B-E) Western blot analysis of HA-NPR1 showing the difference in electrophoretic mobility of phosphorylated Npr1p (Npr1p P $^{\text {) and the }}$ dephosphorylated form, Npr1p, following treatments with rapamycin, PPase or a genetic mutation of MYO1 (see Methods for details). Arrows point to the expected positions of the Npr1 p -phosphorylated form (100 kiloDaltons, kDa) and Npr1 p-dephosphorylated form (85 kDa). Protein extracts were analyzed from A) wild-type (wt) $(10 \mu \mathrm{g}), \mathbf{B})$ wild-type (wt) (10ug), C) myo1 $\Delta$ (40ug), and D) chs2 $\Delta$ (20ug),and E) fks1 $\Delta$ (20ug).

electrophoretic mobility of Npr1p in chs2 $($ Figure 2D) and $f k s 1 \Delta$ (Figure 2E) control strains behaved similar to the wt (Figure 2B). Phosphatase treatment did not change the electrophoretic mobility of Nprlp in the myo1 $1 \Delta$ extracts supporting our hypothesis that TORC1 is down regulated (Figure $2 \mathrm{C}$, lanes 1 and 2). Introduction of a tor $1 \Delta$ mutation into the myols strain did not produce any change in the electrophoretic migration of Nprlp compared to the myols single mutant (Figure 3A). This was also consistent with the notion that TORC1 is inhibited in the myo1 $\Delta$ strain. These observations suggest that the myo1 $\Delta$ strain is distinct from the other cell wall stress models because despite the similarity between these strains which have the
PKC1 CWIP activated, the TORC1 activity was inhibited in the myo1 $\Delta$ strain but not in the cell wall mutants tested (chs $2 \Delta$ and $f k s 1 \Delta$ ) (see Discussion for details).

The SIT4 gene encodes a protein phosphatase that is responsible for dephosphorylation of Npr1p in vivo during nutrient starvation (Figure 2A) [51]. TORC1 when active, phosphorylates Tap42p, which then binds and keeps Sit4p inactive [57]. Thus, Sit4p activity is negatively regulated by TORC1 [58]. In previous studies, Npr1p was shown to maintain the hyperphosphorylated state in a sit $4 \Delta$ mutant treated with rapamycin indicating that its dephosphorylation was directly dependent on Sit4p activity [50,53]. To establish that 


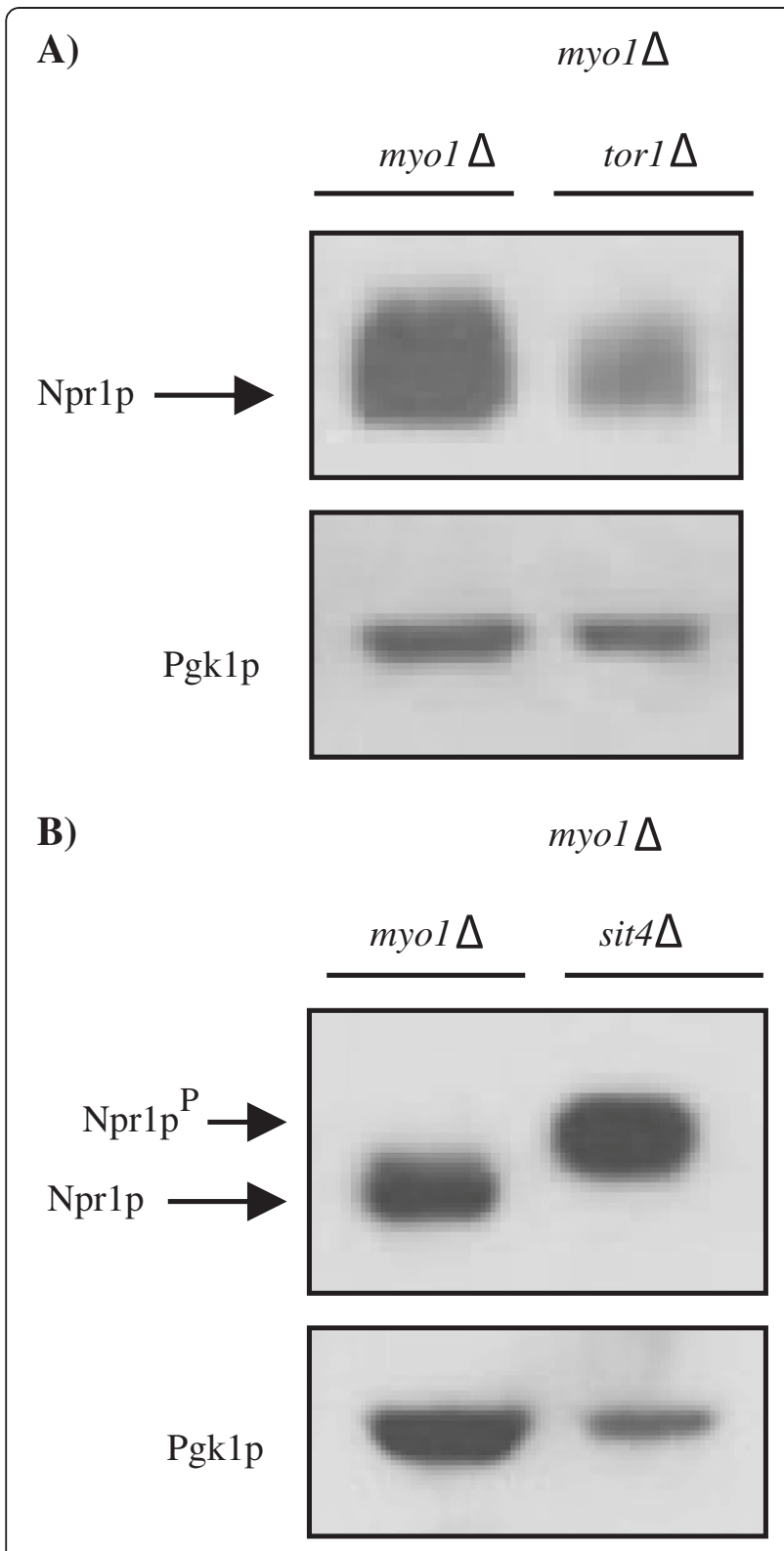

Figure 3 TORC1 is down regulated and Npr1p dephosphorylation is Sit4p dependent in myo1 $\Delta$ strains. Protein extracts from A) myol $\Delta(40 \mu \mathrm{g})$, myo $1 \Delta \operatorname{tor} 1 \Delta(20 \mu \mathrm{g})$ and $\mathbf{B})$ myo $1 \Delta$ sit $4 \Delta(20 \mu \mathrm{g})$ mutant strains each expressing an HA-NPRT plasmid were analyzed by Western blot. Each membrane was probed with anti-HA and anti-PGK1 antibodies. Pgk1p was used as a control. Arrows point to the expected positions of the Npr1 $p^{p}$-phosphorylated form and Npr1p-dephosphorylated form.

dephosphorylation of Npr1p employs the same mechanism in myo1 $\Delta$, we conducted a Western blot analysis of Npr1p in a myo1 $\Delta$ sit4 $\Delta$ strain (Figure 3B). Absence of Sit4p activity in the myo1s strain resulted in the accumulation of the slow-migrating hyperphosphorylated Nprlp. This result supports that the myo1s dephosphorylation of Npr1p is via Sit4p.
TOR signaling activity was previously reported to negatively regulate the PKC1 CWIP [59] because rapamycin treatment resulted in up regulation of $P K C 1$ activity. Our new observations show that TORC1 was repressed in myo1 $1 \Delta$ cells while we had previously shown that $P K C 1$ activity was up regulated in these strains $[4,6]$. To determine if the repression of TORC1 activity in myo1s cells is responsible for up regulation of the PKC1 pathway, we treated myo1 1 cells with rapamycin and monitored Slt2p/Mpk1p hyperphosphorylation (referred to as P-Slt2p from here on) by Western blot analysis (see Methods). As previously reported, down regulation of TORC1 activity in wt cells treated with rapamycin resulted in up regulation of $P K C 1$, reflected by an accumulation of P-Slt2p (Figure 4A). In untreated myo1s cells, there was an accumulation of P-Slt2p as described previously (Figure 4A). There was no significant increase in P-Slt2p levels following rapamycin treatment in these cells (Figure 4B, lanes 1 and 2). This observation supports the aforementioned result [59] that down regulation of TORC1 activity is correlated to the up regulation of $P K C 1$.

To analyze this putative cross-talk further, we assayed the relative levels of P-Slt2p in a myo1 $\Delta$ tor $1 \Delta$ strain. In the absence of Tor1p, a myo1 $1 \Delta$ tor $1 \Delta$ strain maintained significant steady state levels of P-Slt2p at approximately $50 \%$ of the myo1A- levels (Figure 4B, lane 5), while treatment with rapamycin did not generate a significant change in these levels (Figure 4B, lane 6). A tor $1 \triangle$ single mutant activated PKC1 at low levels (Figure 4B, lanes 3 and 4).

To determine if these strains presented a growth defect we tested wt, myo1 $1 \Delta$ tor $1 \Delta$ and myo1 $1 \Delta$ tor $1 \Delta$ strains for cell viability using a serial dilution assay (Figure 4C). The myo1 $\Delta$ strain exhibited a viability range similar to the wt strain. Surprisingly, the tor $1 \Delta$ strain showed increased viability through the $10^{2}$ cells $/ \mathrm{ml}$ range, consistent with previous studies that showed that Torlp functions were not essential for cell viability. Despite having P-Slt2p present (Figure 4B, lane 5) the myo1 $\Delta$ tor $1 \Delta$ strain presented a reduction in cell viability of approximately four orders of magnitude (Figure 4C, bottom row). Therefore, down regulation of TORC1 appears to be favorable to maintain viability in the myo1s strain while a complete absence of Torlp in this strain is detrimental. These results imply that Tor1p may have a predominant role in the TORC1 functions with less activity attributed to the Tor2p in this complex. However, the residual activity in the TORC1 complex was

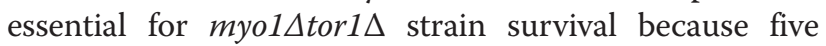
days treatment with the IC50 of rapamycin (44nM) resulted in a 10-fold further reduction of growth (data not shown). 

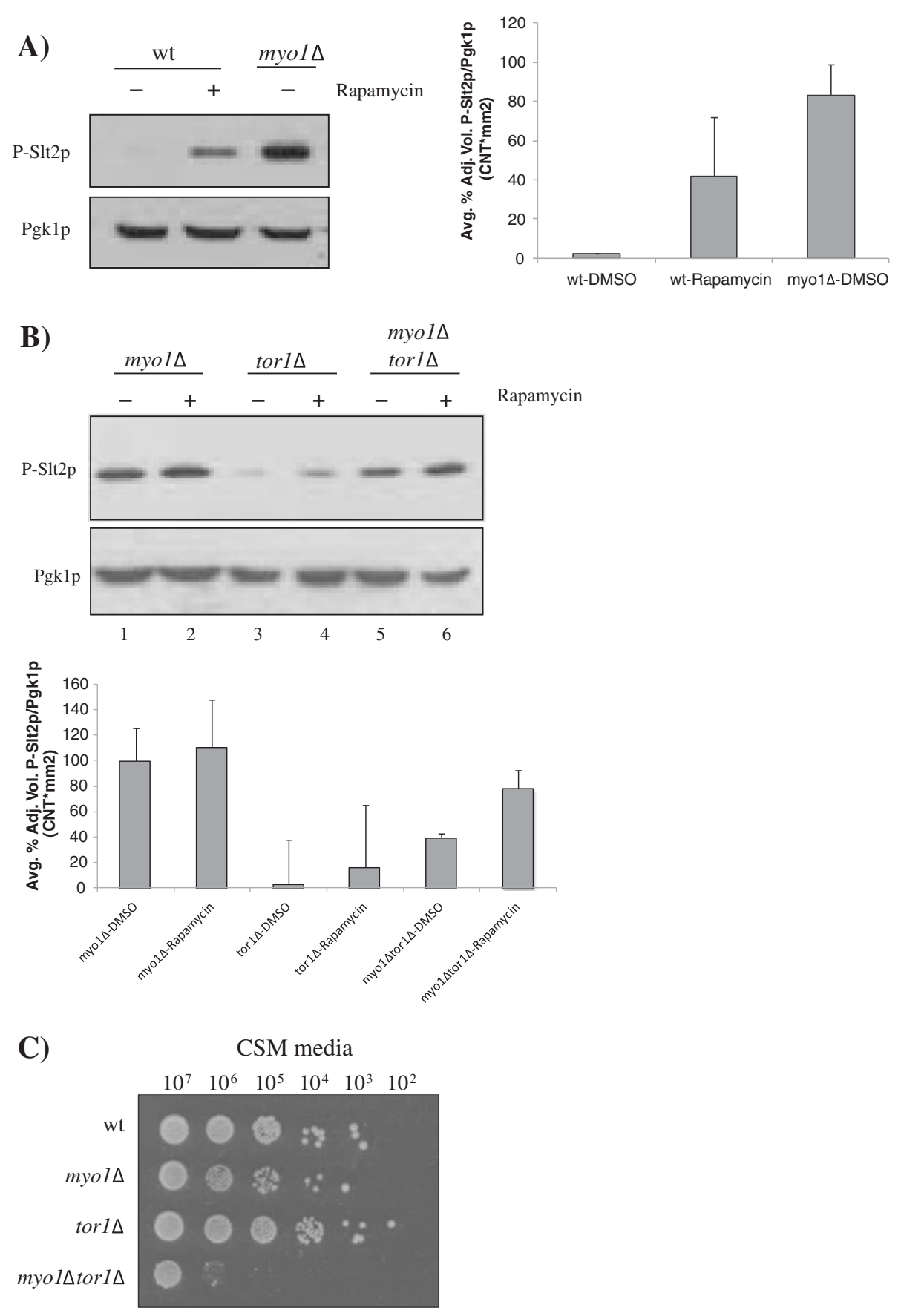

Figure 4 Inverse correlation between TORC1 and PKC1 activities. A) The PKC1 pathway was activated in wt cells upon inhibition of TORC1 with rapamycin. This pathway is constitutively activated in myo1 $\Delta$ cells. A-B) All histograms show the ratio of the intensities of each P-Slt2p band relative to the intensity of its Pgk1p loading control, averaged from duplicate experiments. Error bars represent STDError mean. B) Steady state levels of hyper phosphorylated SIt2p (P-SIt2p, $55 \mathrm{kDa}$ ) were assayed by Western blot using equal amounts of protein extract $(50 \mu \mathrm{g})$ from $\mathrm{myo} 1 \Delta$, tor $1 \Delta$, and myo $1 \Delta$ tor $1 \Delta$ strains treated with rapamycin (+) or with DMSO alone (-). Pgk1p was used as a loading control. C) Limiting dilution growth assay on agar medium measuring relative viability of wt, myo $1 \Delta$, tor $1 \Delta$, and myo $1 \Delta \operatorname{tor} 1 \Delta$ strains. 10 -fold dilutions are indicated at the top of the image (see Methods for details).

Positive genetic interaction between MYO1 and TOR2:

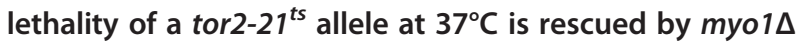
TORC1 is not essential in wt [60] or myo1 strains. In contrast, TORC2 carries out essential functions in yeast cells that are not shared with TORC1 $[21,22,61]$. Growth at the permissive $\left(26^{\circ} \mathrm{C}\right)$ and restrictive $\left(37^{\circ} \mathrm{C}\right)$ temperatures was assayed for strains wt, myo1 $1 \Delta$, chs $2 \Delta$ (each bearing a genomic copy of wild type TOR2), SH121 
A)
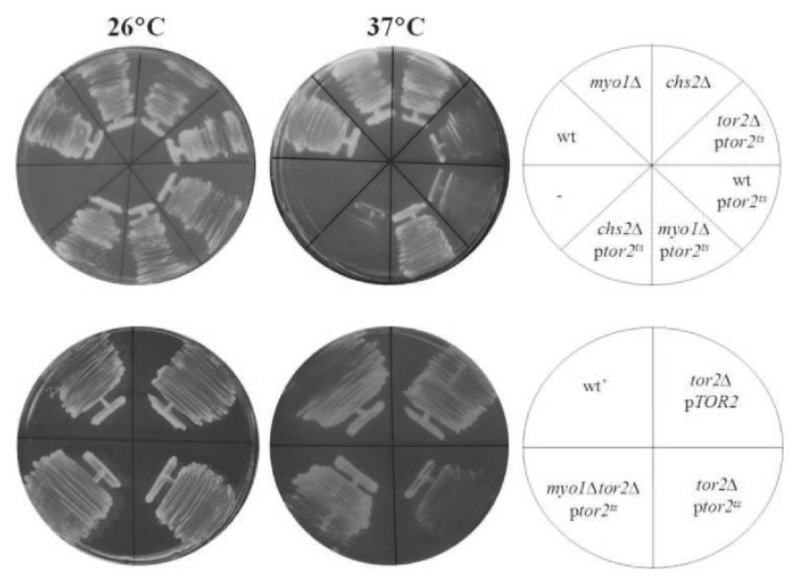

B)

$26^{\circ} \mathrm{C}$

$37^{\circ} \mathrm{C}$

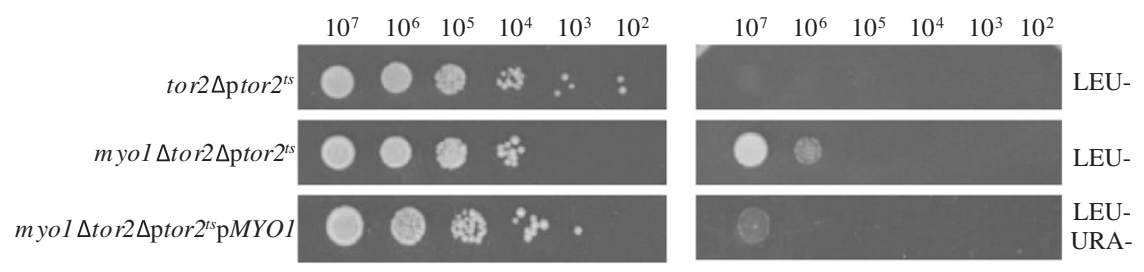

C)

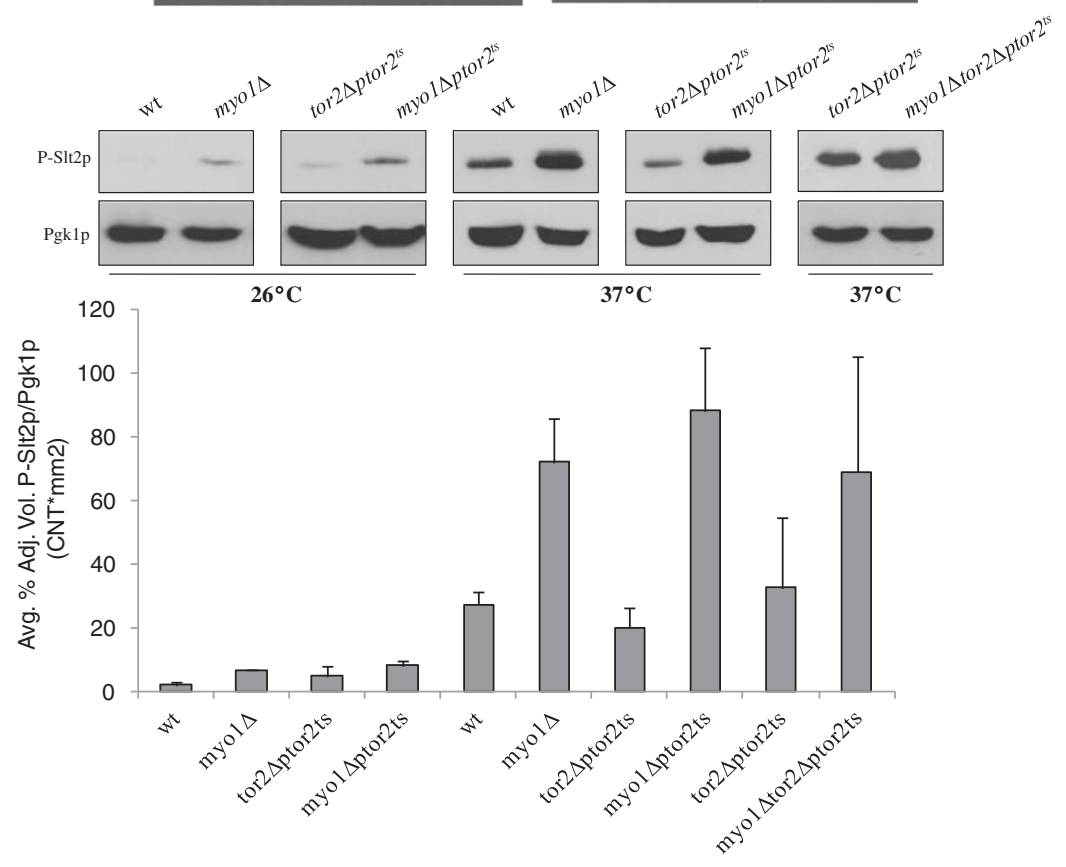

Figure 5 Synthetic rescue of the tor2-2 $21^{\text {ts }}$ phenotype by myo $1 \Delta$. Assay for viability of yeast strains by growth at $26^{\circ} \mathrm{C}$ and $37^{\circ} \mathrm{C}$. Strains tested were wt (YJR24), myo1 $\Delta$, chs2 $\Delta$, wt' (JK9-3da), tor2 $\Delta$ ptor2 ${ }^{\text {ts }}$, wt ptor2 ${ }^{\text {ts }}$, myo1 $\Delta$ ptor2 ${ }^{\text {ts }}$, chs $2 \Delta$ ptor2 ${ }^{\text {ts }}$, tor $2 \Delta$ pTOR2, myo $1 \Delta$ tor $2 \Delta$ ptor $2^{\text {ts }}$. A) Rescue of tor $2-21^{\text {ts }}$ lethality at $37^{\circ} \mathrm{C}$ by myo $1 \Delta$ in the YJR13 strain background (top) and SH121 strain background (bottom). B) Limiting dilution growth assay on agar medium measuring relative viability at $26^{\circ} \mathrm{C}$ and $37^{\circ} \mathrm{C}$ for tor $2 \Delta$ ptor $2^{\text {ts }}$, myo $1 \Delta$ tor $2 \Delta$ ptor $2^{\text {ts }}$, and myo $1 \Delta$ tor $2 \Delta$ ptor $2^{t 5}$ pMYO1 strains. 10 -fold dilutions are indicated at the top of the image (see Methods for details). C) Regulation of Slt2p phosphorylation in myo $1 \Delta$ strains expressing the tor $2-27^{t 5}$ mutation at $37^{\circ} \mathrm{C}$. Steady state levels of P-Slt2p in wt, myo $1 \Delta$, tor $2 \Delta$ ptor $2^{t s}$, and myo $1 \Delta$ ptor $2^{t s}$ were analyzed by Western blot as described previously from cultures grown at $26^{\circ} \mathrm{C}$ and $37^{\circ} \mathrm{C}$. Pgk1p was used as a loading control. Histograms show the ratio of the relative intensities of each P-SIt2p band and its Pgk1p loading control, averaged from duplicate experiments. Error bars represent STD Error Mean. 
(acontrol tor $2 \Delta$ strain that contains a plasmid-borne copy of a temperature-sensitive tor $2-21$ allele, ptor $2^{t s}$ ) and combination strains bearing also the ptor $2^{\text {ts }}$ plasmid. Since TORC2 is responsible for essential cellular functions, the expected outcome was that repression of the tor $2-21^{\text {ts }}$ allele at $37^{\circ} \mathrm{C}$ would be lethal in any strain. Parental strains and mutant strains bearing ptor $2^{\text {ts }}$ were therefore assessed for growth on agar at $26^{\circ} \mathrm{C}$ and $37^{\circ} \mathrm{C}$. As expected, the wt, myo1 $1 \Delta$, and chs $2 \Delta$ strains did not exhibit temperature sensitive growth (Figure 5A, top row). The tor $2 \Delta$ ptor $2^{t s}$ (control), wt ptor $2^{t s}$, and chs $2 \Delta$ ptor $2^{t s}$ strains were viable at $26^{\circ} \mathrm{C}$ and temperature sensitive for growth at $37^{\circ} \mathrm{C}$ indicating dominance of the tor2-21 $1^{\text {ts }}$ mutation (Figure 5A, upper left and upper right respectively). In contrast, the myo1 $1 \Delta$ ptor $^{t s}$ strain presented viable growth at both temperatures (Figure 5A, top row). The suppression of tor $2-21^{t s}$ lethality by myo1A in this strain (YJR13) was also confirmed in the SH121 strain background (Figure 5A, bottom left and bottom right, respectively) to exclude genetic background effects. Growth was also assessed on Leucine dropout medium plates to ascertain that strains transformed with the ptor $2^{t s}$ allele were expressing the plasmid, as observed by the normal growth at $26^{\circ} \mathrm{C}$ [Additional file 1, left plates], and again that the tor 2 $21^{t s}$ defect was suppressed in the absence of the MYO1 gene at $37^{\circ} \mathrm{C}$ independently of the strain background [Additional file 1, right plates]. The positive genetic interaction between myo1 $1 \Delta$ and tor $2-21^{\text {ts }}$ mutations was reverted by complementation with a plasmid-borne copy of the wild type MYO1 gene in myol $1 \Delta$ tor $2 \Delta \mathrm{ptor} 2^{t s} \mathrm{p}$ MYO1 (SH121) (Figure 5B) and also myo1 $\mathrm{ptor}^{t s} \mathrm{p}^{\text {- }}$ MYO1 (YJR13) strains (data not shown).

TORC2 has been shown to have a strong regulatory effect on PKC1 activity in cell wall mutants [29,30]. To explain the observed synthetic rescue of tor $2-21^{\text {ts }}$ lethality by $m y 01 \Delta$, we conducted a Western blot analysis of P-Slt2p levels in the wt, myo1 $\Delta$ (Figure 5C, box1), tor $2 \Delta$ $\mathrm{ptor} 2^{t s}$ and myold $\mathrm{ptor} 2^{t s}$ strains (Figure 5C, box 2) at the permissive temperature. Wt and tor $2 \Delta \mathrm{ptor} 2^{t s}$ strains showed similarly low P-Slt2p levels consistent with growth under non-stress conditions (Figure 5C, box 1 and box 2 respectively). The myo1 (Figure $5 \mathrm{C}$, box 1 ) and myo1s ptor $2^{t s}$ (Figure 5C, box2) strains both presented a higher level of P-Slt2p relative to wt strains at $26^{\circ} \mathrm{C}$, which was also consistent with previous observations that PKC1 is activated in these strains (Figure 4A, lane 3).

To assess if rescue of tor $2-21^{t s}$ lethality at the restrictive temperature by myo1 $\Delta$ was accompanied by a change in PKC1 activity levels, P-Slt2p was analyzed in whole cell extracts from cultures taken at $37^{\circ} \mathrm{C}$ (Figure $5 \mathrm{C}$ boxes 3 and 4). The temperature shift to $37^{\circ} \mathrm{C}$ produced an increase in P-Slt2p levels in all four strains attributable to the heat shock effect that is known to activate the $P K C 1$ pathway $[1,62]$. This suggests that there may exist two pools of Slt2p, one that is activated by the myo1s mutation and one that is activated (or phosphorylated) by the heat stress. Densitometric quantification and normalization of autoradiographs from duplicate experiments established that P-Slt2p levels in the myol $1 \Delta$ ptor $2^{t s}$ strain at $37^{\circ} \mathrm{C}$ were 5 -fold higher than in the tor $2 \Delta$ ptor $2^{t s}$ strain yet were very similar to the myo1 1 single mutant strain at $37^{\circ} \mathrm{C}$ (Figure $5 \mathrm{C}$, bottom panel). However, when we compared P-Slt2p levels between the tor $2 \Delta \mathrm{ptor}^{t_{s}}$ and myo1 1 tor $2 \Delta \mathrm{ptor} 2^{\text {ts }}$ strain, there was no significant difference between them supporting that the rescue effect was not due to Tor2pdependent P-Slt2p up regulation (Figure $5 \mathrm{C}$, box 5 ) or differences in P-Slt2p levels.

\section{Evidence for a cross-talk between Pkc1p, TORC1, and cell wall stress sensor Wsc1p}

Inhibition of TOR functions activates multiple cell wall stress sensor proteins located in the plasma membrane that interact with signaling intermediates through their C-terminus in the cytoplasm [59]. Cell wall stress sensor proteins that belong to the Wsc family and also include the Mid2 proteins, signal positively to activate the $P K C 1$ CWIP [2,32-37]. Under cell wall stress conditions, Wsc1p, Wsc2p and Mid2p are reported to be the principal sensors responsible for activating this pathway $[36,48,49]$. Consistent with the notion that cell wall stress sensors may mediate the stress response in myo1 $1 \Delta$ strains, we have presented evidence that the PKC1 CWIP is activated and essential [4-6] and that TORC1 activity is down regulated in myo1s strains (this study). To test if cell wall stress sensor proteins could, by a cross-talk mechanism, be involved in down regulating the TOR pathway, the myo1 $\Delta$ mutation was inserted in $w s c 1 \Delta$, wsc $2 \Delta$, $w s c 3 \Delta$ and mid $2 \Delta$ mutant strains by standard genetic techniques (see Methods). The single mutants $(w s c 1 \Delta$, wsc $2 \Delta$, wsc $3 \Delta$, mid $2 \Delta)$ and their corresponding double mutant strains (myo1 $\Delta w s c 1 \Delta$, myo1 1 wsc $2 \Delta$, myo1 1 wsc $3 \Delta$, myo1 $\Delta$ mid $2 \Delta$ ) were tested for TORC1 activity and cell viability (only the results for Wsc1p are shown, Figure 6).

Relative TORC1 activity levels for the wt and myo1 $1 \Delta$ strains were previously shown (Figures $2 \mathrm{~B}$ and $2 \mathrm{C}$ respectively), while the results for $m y o 1 \Delta w s c 2 \Delta$, myo1 1 wsc $3 \Delta$ and myo1 1 mid $2 \Delta$ strains were also consistent with down regulated TORC1 activity in these strains (data not shown). In contrast, the myo1 1 wsc1 $1 \Delta$ double mutant strain exhibited a result that was consistent with a fully active TORC1 (Figure 6A, lane 1) as judged by the relative decrease in electrophoretic mobility normally exhibited by $\mathrm{Npr}_{\mathrm{p}} \mathrm{p}$, and the restored sensitivity of $\mathrm{Npr}^{\mathrm{p}} \mathrm{p}^{\mathrm{P}}$ electrophoretic mobility 


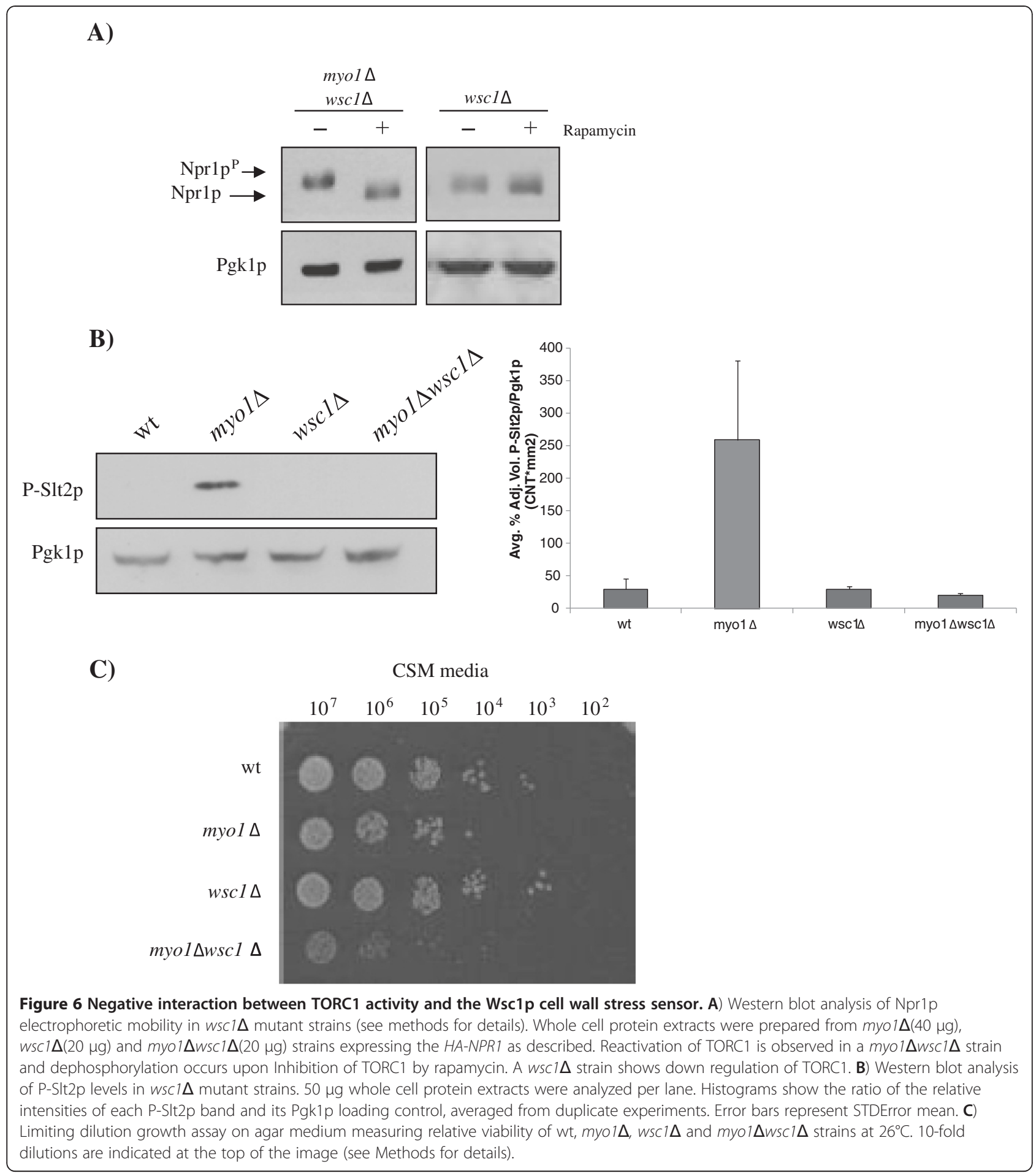

to rapamycin treatment (Figure 6A, lane 2). Also, like the myol $\Delta$ and $w s c 1 \Delta$ strains (Figure 6A, lanes 3 and 4 ), preliminary results show that $w s c 2 \Delta, w s c 3 \Delta$, and mid $2 \Delta$ single mutant strains (data not shown) exhibited a rapamycin-insensitive Npr1p electrophoretic mobility that was consistent with down regulation of TORC1. These results indicate that absence of these cell wall stress sensors represents a cell stress and supports the idea that they also play a role during normal cell growth. We therefore conclude from these results that Wsc1p may be associated with the regulation of TORC1 in both the wt and myo1 $\Delta$ strains.

Because TORC1 and PKC1 activities maintain an inverse relationship [59], we predicted that a re-activation 


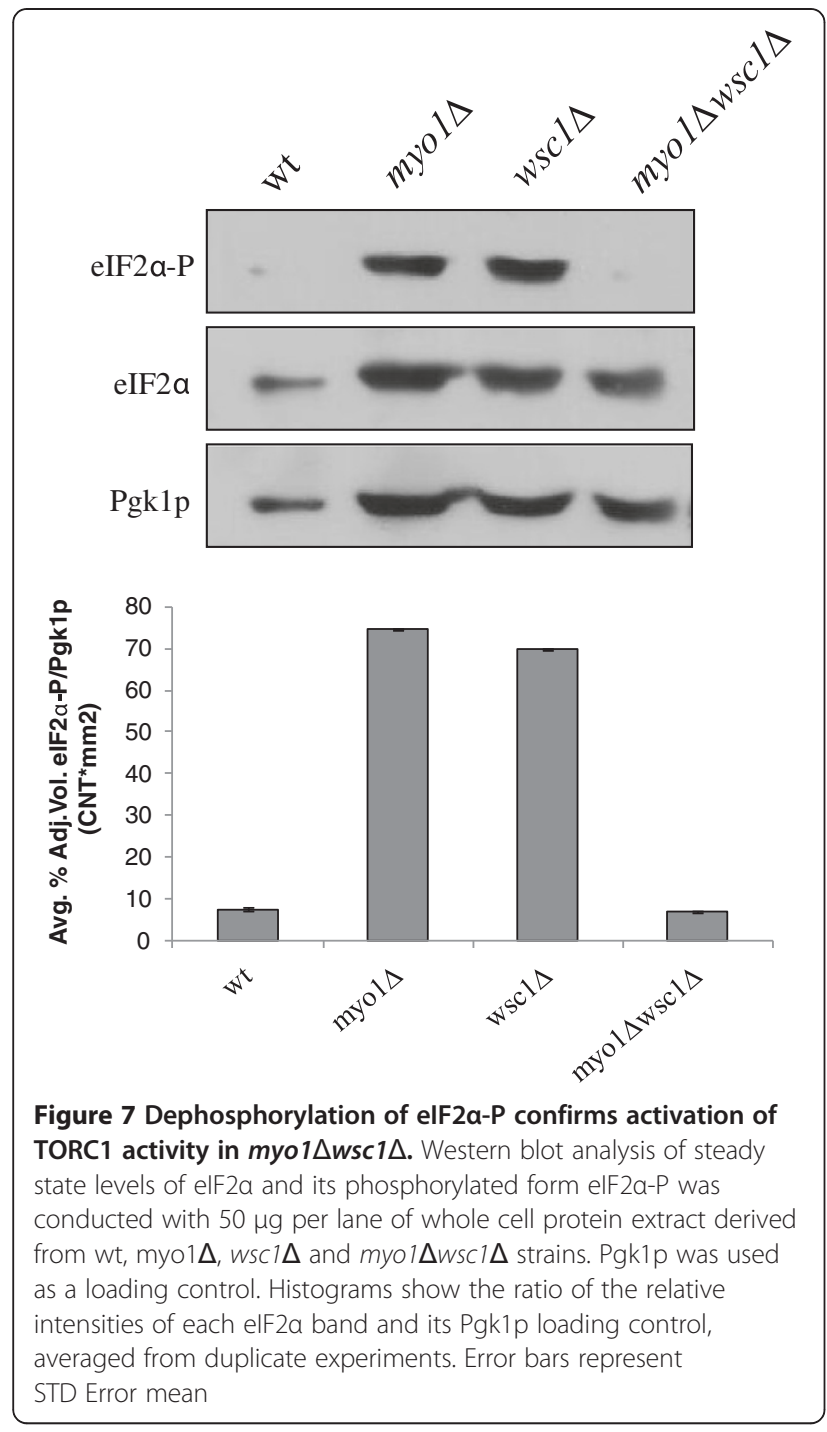

of the TORC1 observed in the myo1 1 wsc1 $1 \Delta$ strain would exert an inhibitory effect on the PKC1 pathway. Consistent with this hypothesis, the myo1 $\Delta w s c 1 \Delta$ strain failed to activate the PKC1 pathway as evidenced by undetectable levels of P-Slt2p relative to a myo1s single mutant where PKC1 was activated (Figure 6B). Cell viability analysis revealed a reduction in growth of approximately one order of magnitude in the myo1 $1 \Delta w s c 1 \Delta$ double mutant strain relative to the myo1 $\Delta$ strain and two orders of magnitude relative to wt and $w s c 1 \Delta$ strains that grew comparably well (Figure 6C).

We then tested eIF2 $\alpha$ phosphorylation levels as an additional readout of TORC1 status [63]. Previous studies showed that TORC1 down regulation in myo1 $1 \Delta$ was evidenced by a large ( 2 fold) accumulation of phosphorylated eIF2 $\alpha$ (eIF2 $\alpha-\mathrm{P})$ produced by a TORdependent activation of Gcn2p protein kinase (Figure 7, top panel) [17]. The myoldwsc1 $1 \Delta$ mutant combination that restored wild type electrophoretic mobility to Npr1p
(Figure 6A) also restored eIF2 $\alpha$-P to its active unphosphorylated state, eIF2 $\alpha$ (Figure 7, top panel, lane 4), thereby confirming that TORC1 was being reactivated in this mutant. Likewise, the accumulation of eIF $2 \alpha-\mathrm{P}$ in the wsc1 $1 \Delta$ mutant confirmed that TORC1 activity was down regulated in this mutant (Figure 7, top panel, lane $3)$. Control extracts from the wt and myo1 $\Delta$ strains were consistent with previously reported results [17]. Total eIF2 $\alpha$ confirmed that the proposed changes in eIF2 $\alpha-P$ were due to phosphorylation rather than a change in steady state levels of eIF2 $\alpha$ (Figure 7, middle panel).

\section{Discussion}

Yeast cells must respond rapidly and effectively to alterations in the environment in order to survive stressful conditions. These processes require the involvement of signal transduction pathways such as TOR and PKC1. The PKC1 dependent CWIP is the first line of response to cell wall damage in the yeast Saccharomyces cerevisiae $[13,14]$. Transduction of the signal begins with the cell wall stress sensor proteins Wsc1p and Mid2p at the

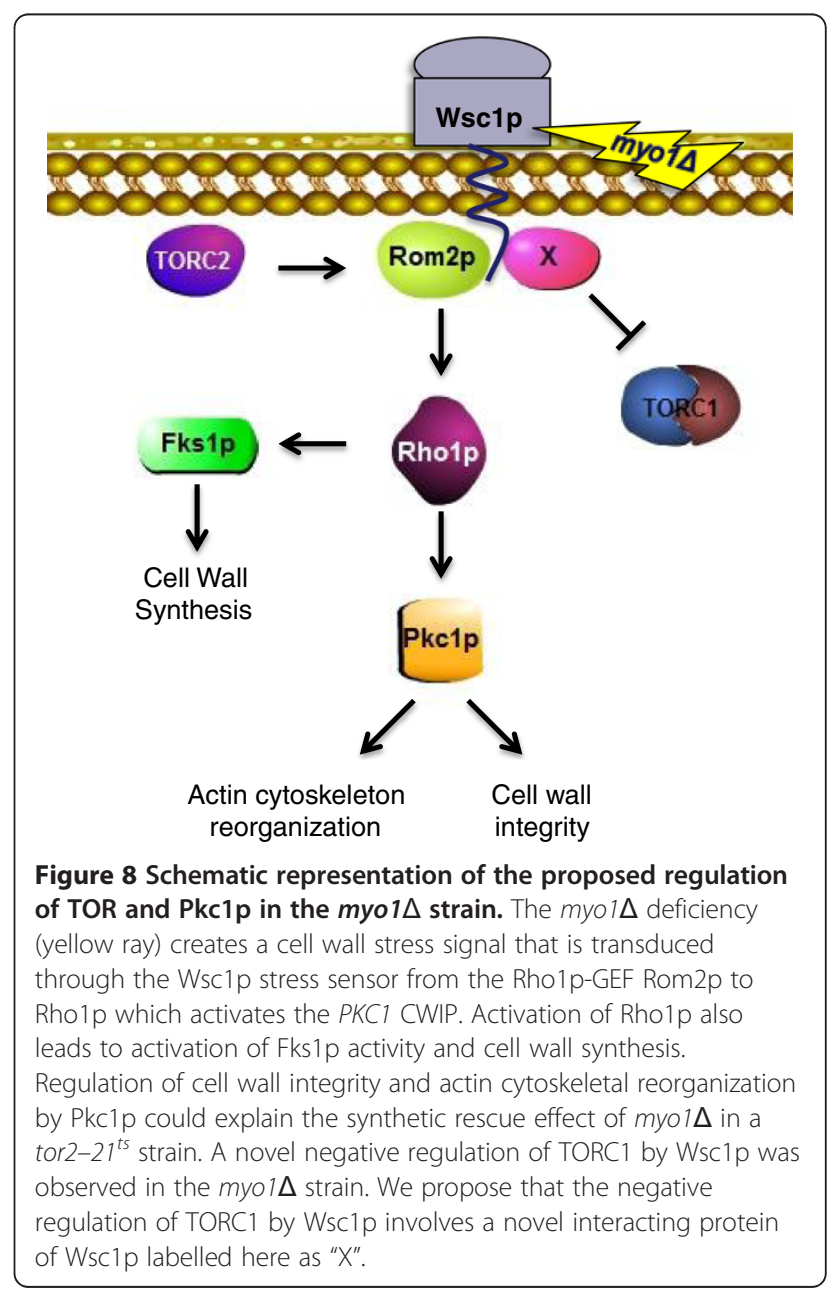


plasma membrane and proceeds through Rom2p and Rho1p to the PKC1 CWIP that ends with activation of the MAP kinase, Slt2p [13,48] (Figure 1). Downstream, the transcription factor $\mathrm{Rlm} 1 \mathrm{p}$ activates nuclear genes involved in cell wall synthesis and remodeling to produce a cell wall stress response that increases the survival potential of the yeast cell $[9,10]$. We have shown in prior studies that the $P K C 1$ pathway is continuously activated in myo1 $\triangle$ strains $[4,6]$. This response is further characterized here in the myo1 $\Delta$ strains. In addition to the up regulation of the CWIP we found that TORC1 was down regulated to enhance cell survival and we provide evidence of cross-talk between the two signaling pathways.

Nprlp is a protein kinase that regulates the amino acid permease Gap1p to transport secondary nitrogen sources into the cell for the restoration of amino acid precursor levels and protein synthesis $[51,64,65]$. When TORC1 is down regulated by nutrient starvation or rapamycin treatment, Npr1p becomes dephosphorylated by the protein phosphatase Sit4p, thereby activating its biochemical function $[50,51,53]$ Furthermore, inactivation of TORC1 results in downregulation of ribosome and protein synthesis [59]. When we assayed the relative status of TORC1 activity in a myo1 $1 \Delta$ strain, we observed that Npr1p was maintained in the dephosphorylated state and demonstrated that the Nprlp phosphorylation state was directly dependent on TORC1 and Sit4p activities. Therefore, we established that the TORC1 complex is found in a predominantly inactive state in the myold strain. The implications of such a metabolic state led us to believe that the survival of this strain is directly linked to this observation. However, the complete absence of Tor1p by genetic deletion (tor1 $\Delta$ ) was detrimental for survival of the myo1s strain, supporting that a precise level of TORC1 activity must be maintained for its survival. Furthermore, complete inhibition of TORC1 activity by rapamycin treatment of a myo1 $1 \Delta$ tor $1 \Delta$ strain was lethal for growth, further supporting the idea that minimal levels of TORC1 activity are essential. Conversely, the tor $1 \Delta$ single mutant was shown to acquire increased fitness, which was consistent with the proposed role of mTOR and TOR in regulating longevity and replicative life span extension respectively [24-27].

It was previously known that the TORC1 pathway plays a role in the response to cell wall stress by a negative regulation of the PKC1 CWIP under nutrient rich conditions [59] (Figure 1). Under myo1 $\Delta$ conditions, we observed a clear inverse biochemical correlation between TORC1 and Pkc1p activities. This raised the question, is there a common upstream regulator of the two pathways? Our results are strongly suggestive that Wsc1p acts as a common upstream regulator of TORC1 and $P K C 1$ by exerting a positive role in the activation of the
PKC1 CWIP and a negative role in the down regulation of TORC1 by an unknown mechanism. We do not propose that TORC1 and Wsc1p interact directly. Most likely, the mechanism involves an undetermined protein interactor of Wsc1p (labeled "X" in Figure 8). Recently, we have identified several novel Wsc1p interacting proteins (unpublished results) and suspect that some may function as a signaling intermediate between Wsc1p and TORC1. However, pending future studies, it is not known whether or not these Wsclp interactors inhibit TORC1.

Our findings showed that chs $2 \Delta$ and $f k s 1 \Delta$ mutant strains strongly activated the PKC1 CWIP yet maintained normal TORC1 activity levels. We are therefore confronted with variable signaling outputs exiting from the cell wall stress sensors. In particular, disruption of cell wall integrity by these mutants leads to activation of the PKC1 CWIP; however, only the disruption of cytokinesis in a myo1 $\Delta$ strain leads to both activation of the PKC1 CWIP and down regulation of TORC1 (Figure 8). This finding is consistent with the transcriptional profiles we have determined previously, where myo1 $1 \Delta$ only regulated half of the CWIP fingerprint genes, while $f k s 1 \Delta$ and chs $2 \Delta$ profiles were more like other cell wall damage profiles $[4,5]$. This reinforces the idea that $m y o 1 \Delta$ activates a cell signaling program that is distinct from other cell wall mutants. We propose that in addition to its filament assembly function, the tail domain may serve as a scaffold (or guide) for the assembly of interacting protein complexes at the cytokinetic ring that are important for myosin function [66]. Therefore, disruption of these putative protein assemblies by a genetic deletion of the $M Y O 1$ gene may activate the cell wall stress sensors Wsc1p and Mid2p in a different manner than in the chs $2 \Delta$ and $f k s 1 \Delta$ mutants. The non-muscle myosin heavy chain (Myolp) of budding yeast has been shown to have independent functions associated with the head and tail domains of the protein [67]. The tail domain contains a Minimum Localization Domain (MLD) that is sufficient to target the myosin heavy chain to the bud neck independently of the actin-binding site that is encoded within the head domain [68]. Therefore, despite the common activation of the PKC1 CWIP among the myol $1 \Delta$, chs $2 \Delta$ and $f k s 1 \Delta$ mutant strains, we hypothesize that the inhibition of TORC1 by Wsclp is unique to the myo1 $\Delta$ mutant and may be triggered by the disruption of specific protein-protein interactions in the putative Myolp scaffold at the cytokinetic ring.

The final question that arises from these results is, how does the myo1 $\Delta$ mutant rescue tor $2-21^{t s}$ lethality? Strains that carry the temperature-sensitive gene of TOR2 $\left(\right.$ tor $\left.2^{t s}\right)$ arrest growth at the restrictive temperature $\left(37^{\circ} \mathrm{C}\right)$. This lethality is thought to be caused by the lack of TORC2 activity, decreased RHO1 activation 
[21], the lack of actin organization and cell lysis probably due to cell wall defects [69]. The lethality has been shown to be rescued in several different ways. One way is by growth on nonfermentative carbon sources (i.e. raffinose) but not by nonfermentable carbon sources (i.e. glycerol or ethanol) [69]. A second way in which tor $2^{t s}$ lethality can be circumvented is by treatment with agents that cause cell integrity stress (i.e. 0.005\% SDS) [30]. A third way in which the tor $2^{t s}$ lethality can be rescued is by the osmotic stabilizer, sorbitol, again suggesting that the cell wall is somehow compromised. Finally, there are several genes that have been shown to suppress the lethality of tor $2^{t s}$ lethality. One example is yeast PAS kinase overexpression (a gene involved in glucose partitioning in the cell) which is thought to suppress the $\operatorname{tor}^{\text {ts }}$ lethality by RHO1-dependent activation of $P K C 1$ and actin rearrangement, activation of FKS1 and cell wall synthesis, or both [69]. These observations have lead to the idea that cell growth and survival is a product of signals derived from cell integrity and nutrient availability [69]. In this work we provide evidence for rescue of tor $2^{\text {ts }}$ lethality by the deletion of the MYO1 gene. We propose that myol $1 \Delta$ rescues the tor $2^{t s}$ lethality by invoking both strategies described above, namely, by activating a starvation type response (TOR) and the cell wall integrity pathway ( $P K C 1$ CWIP), most likely through the reorganization of the actin cytoskeleton. However, unlike the results of Cardon et al. [69] where the essential Rho1p GEF was Rom2p, the roles of Rom1p and Rom2p appear to be redundant for the proposed myo1s rescue mechanism (data not shown).

\section{Conclusions}

We have shown that cross-talk between the PKC1 and TOR signaling cascades occur under the myo1 $\Delta$ stress condition. TORC1 activity was found to be inversely correlated with activation of the PKC1 pathway while both Torlp and Pkclp act as positive regulators of viability in the myo1s strain. Synthetic rescue of tor $2-21^{t s}$ lethality by myo1A points to the PKC1-dependent reorganization of the actin cytoskeleton as the possible rescue mechanism. The data presented supports that in addition to its known role in signaling to the PKC1 CWIP, Wsc1p may also function as an upstream regulator of TORC1.

\section{Methods}

\section{Strains and media}

Saccharomyces cerevisiae strains used in this study are listed in Table 1. Dr. Brian C. Rymond kindly provided the TOR1, SIT4 and WSC1 null mutation strains. The

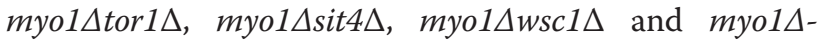
tor $2 \Delta$ ptor $2^{\text {ts }}$ double mutants were constructed by a disruption of the MYO1 gene with a HIS5 module by homologous recombination using a PCR based method. Strains tor $2 \triangle \mathrm{p} T O R 2$ and tor $2 \Delta \mathrm{p}$ tor $2^{\text {ts }}$ were kindly provided by Dr. Michael N. Hall. The composition of complete synthetic media (CSM) for wild type cells was complemented with $2 \%$ Glucose and $1 \mathrm{X}$ Nitrogen base without amino acids. The composition of rich medium (YPD)/G for tor $1 \Delta$, sit4 $\Delta$, and wsc1 $1 \Delta$ strains was complemented with $2 \%$ Glucose and $200 \mathrm{ug} / \mathrm{mL}$ G418 (Geneticin). Histidine dropout media (CSM HIS-) was used for double mutant lacking the MYO1 gene; while Leucine dropout media (CSM LEU-) was used for the maintenance of plasmids, each one complemented with $2 \%$ Glucose and the appropriate nitrogen base without amino acids. Cultures were grown overnight at $26^{\circ} \mathrm{C}$ to mid-logarithmic phase with an optical density between 0.5-0.8 AU $\left(\mathrm{OD}_{600}\right)$ with continuous shaking at $225 \mathrm{rpm}$. A $1 \mathrm{mg} / \mathrm{mL}$ stock solution of rapamycin (SIGMA) was dissolved in the drug vehicle 100\% DMSO. To inhibit TORC1, cultures were treated with rapamycin for $1 \mathrm{~h}$ with drug vehicle alone (DMSO) 100\% or with a half maximal (50\%) growth inhibitory concentration of rapamycin at a final concentration of $60 \mathrm{nM}(54.85 \mathrm{ng} /$ $\mathrm{mL}$ ) for wt cells and $44 \mathrm{nM}(36.56 \mathrm{ng} / \mathrm{mL})$ for mutant cells, prior to harvesting. Cultures bearing plasmid ptor $^{\text {ts }}$ were grown to mid-log phase in CSM LEUmedium, and were then diluted to an $\mathrm{OD}_{600}$ of 0.5 in pre-warmed media. Cultures were shaken at $225 \mathrm{rpm}$ at $37^{\circ} \mathrm{C}$ for $1 \mathrm{~h}$.

\section{Plasmid and genetic techniques}

Plasmid pHA-NPR1 (pEJ23) consists of YEplac181 (LEU2) expressing a functional N-terminally HA-tagged NPR1 under its own promoter [53], kindly provided by Dr. Estela Jacinto. Plasmid YCplac111::tor2-21 ${ }^{\text {ts }}$ (LEU2) containing a temperature sensitive tor $2-21^{\text {ts }}$ allele [21] was kindly provided by Dr. Michael N. Hall. Escherichia coli strain DH5 $\alpha$ was used for the propagation and isolation of plasmids. Yeast transformations were performed by the Lithium acetate procedure. Yeast plasmid DNA was isolated by an adaptation from the QIAGEN QIAprep Spin miniprep kit.

\section{Western blot analysis}

Whole yeast cell protein extracts were prepared by harvesting and lysing cell cultures by vortexing with glass beads for $20 \mathrm{~s}$ with $3 \mathrm{~min}$ intervals on ice (repeated 3 times). Lysis buffer contained $50 \mathrm{mM}$ Tris- $\mathrm{HCl} \mathrm{pH}$ 7.5, 10\% Glycerol, 1\% TritonX-100, 0.1\% SDS, $150 \mathrm{mN} \mathrm{NaCl}$, and $5 \mathrm{mM}$ EDTA, supplemented with 5X Protease Inhibitor Cocktail (50X stock; Roche) and $10 \mathrm{mM}$ PMSF. Cell lysates were centrifuged at $13,000 \mathrm{rpm}$ for $10 \mathrm{~min}$ at $4^{\circ} \mathrm{C}$; the supernatant was 
Table 1 Strains used in this study

\begin{tabular}{|c|c|c|}
\hline Strain & Genotype & Source \\
\hline YJR12,YJR24_1 (wild type, wt) & MAT a trp1 ura3 leu2-3 his3 $\Delta 1$ met- $A D E+A R G+c^{2} h^{R}$ & Lab. Strain \\
\hline JK9-3da (wt') & MAT a leu2-3,112 trp ura3 rmel his4 HMLa & M. Hall \\
\hline YJR13 (myold) & MAT a trp1 ura3 leu2-3 his3 $\Delta 1$ met- ADE + ARG + cyh $h^{R}$ myo $1 \Delta:$ HIS5+ & Lab. Strain \\
\hline YFR22 $(f k s 1 \Delta)$ & MAT a trp1-289 ura3-52 leu2-3, 112 his3 $\Delta 1 \mathrm{ADE}+\mathrm{ARG}+\mathrm{cyh}^{\mathrm{R}} \mathrm{fks} 1 \Delta: \mathrm{k} a n M X 4$ & F. Rivera \\
\hline YFR23 (chs2 $\Delta$ ) & MAT a trp1-289 ura3-52 leu2-3, 112 his3 $\Delta 1$ ADE + ARG + cyh $^{R}$ chs2 $\Delta: k a n M X 4$ & F. Rivera \\
\hline YJR066W (tori $\Delta)$ & MAT a his $3 \Delta 1$ leu $2 \Delta 0$ lys $\Delta 0$ ura3 $\Delta 0$ tor $1 \Delta: k a n M X 4$ & B. Rymond \\
\hline YGP1 (myol $1 \Delta$ tor $1 \Delta)$ & MAT a his $3 \Delta 1$ leu2 $\Delta 0$ lys $\Delta 0$ ura3 $\Delta 0$ tor1 $\Delta: k a n M X 4$, myo $1 \Delta .: H I S 5+$ & This study \\
\hline YOR008C (wsC1A) & MAT a his $3 \Delta 1$ leu2 $\Delta 0$ lys $\Delta 0$ ura3 $\Delta 0$ wsc1 $\Delta:$ :kanMX4 & B. Rymond \\
\hline YES1 (myol $\Delta w s c 1 \Delta)$ & MAT a his $3 \Delta 1$ leu2 $\Delta 0$ lys $\Delta 0$ ura3 $\Delta 0$ wsc1 $\Delta:$ :kanMX4, myo $1 \Delta .: H I S 5+$ & E. Santiago \\
\hline MH346-1a/pJK3-3 & JK9-3da ade2 tor2::ADE2/pSEY18::TOR2 & M. Hall \\
\hline $\mathrm{SH} 121$ (tor $2 \Delta$ ptor $\left.2^{\text {ts }}\right)$ & JK9-3da ade2 tor2::ADE2/YCplac111::tor2-21 $1^{\text {ts }}$ & M. Hall \\
\hline YGP5 (myo $1 \Delta$ tor2 $\Delta$ ptor2 ${ }^{\text {ts }}$ ) & JK9-3da ade2 tor2::ADE2/YCplac111::tor2-21 $1^{\text {ts }}$ myo1A::HIS5+ & This study \\
\hline YJR12/pEJ23 (wt pHA-NPR1) & MAT a trp1 ura3 leu2-3 his3 $\Delta 1$ met- ADE $+A R G+c y h^{R}$, pHA-NPR1 & This study \\
\hline YJR13pEJ23 (myo 1D pHA-NPR1) & MAT a trp1 ura3 leu2-3 his $3 \Delta 1$ met- ADE + ARG + cyh ${ }^{R}$, myo $1 \Delta *: H I S 5+$ pHA-NPR1 & This study \\
\hline$(\mathrm{YFR} 22 \mathrm{pEJ} 23)(f \mathrm{ks} 1 \Delta \mathrm{pHA}-\mathrm{NPR} 1)$ & $\begin{array}{l}\text { MAT a trp1-289 ura3-52 leu2-3, } 112 \text { his3 } \Delta 1 \text { ADE }+ \text { ARG }+ \text { cyh }^{R} \text { fks } 1 \Delta: k a n M X 4, \\
\text { pHA-NPR1 }\end{array}$ & This study \\
\hline YFR23pEJ23 (chs2DpHA-NPR1) & $\begin{array}{l}\text { MAT a trp1-289 ura3-52 leu2-3, } 112 \text { his } 3 \Delta 1 \text { ADE }+ \text { ARG }+ \text { cyh }{ }^{R} \text { chs } 2 \Delta: \text { :kanMX4, } \\
\text { pHA-NPR1 }\end{array}$ & This study \\
\hline YJR066WpEJ23 (tor1 $\triangle \mathrm{pHA}-N P R 1)$ & MAT a his $3 \Delta 1$ leu2 $\Delta 0$ lys $\Delta 0$ ura3 $\Delta 0$ tor $1 \Delta:: k a n M X 4$, pHA-NPR1 & This study \\
\hline 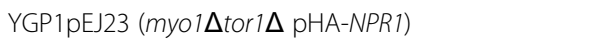 & MAT a his $3 \Delta 1$ leu2 $\Delta 0$ lys $\Delta 0$ ura3 $\Delta 0$ tor $1 \Delta *$ kanMX4 myo $1 \Delta *: H I S 5+$, pHA-NPR1 & This study \\
\hline YDL047W pEJ23 (sit4DpHA-NPR1) & MAT a his $3 \Delta 1$ leu2 $\Delta 0$ lys $\Delta 0$ ura3 $\Delta 0$ sit4 $\Delta: k a n M X 4$, pHA-NPR1 & This study \\
\hline YGP3pEJ23 (myo1 $\triangle$ sit4 $\Delta$ pHA-NPR1) & MAT a his $3 \Delta 1$ leu2 $\Delta 0$ lys $\Delta 0$ ura3 $\Delta 0$ sit4 $\Delta:$ :kanMX4 myo $1 \Delta:: H I S 5+$, pHA-NPR1 & This study \\
\hline YOR008C pEJ23 (wsc1DpHA-NPR1) & MAT a his $3 \Delta 1$ leu2 $\Delta 0$ lys $\Delta 0$ ura3 $\Delta 0$ wsc $1 \Delta:$ :kanMX4, pHA-NPR1 & This study \\
\hline YES1pEJ23 (myo1Dwsc1D pHA-NPR1) & MAT a his3 $\Delta 1$ leu $2 \Delta 0$ lys $\Delta 0$ ura3 $\Delta 0$ wsc1 $\Delta:$ kanMX4 myo $1 \Delta: \cdot H I S 5+$, pHA-NPR1 & This study \\
\hline YJR24_1/YCplac111 (wt ptor2ts) & MAT a trp1 ura3 leu2-3 his3 1 met- ADE + ARG + cyh $^{R}$, YCplac111::tor2-21 $7^{\text {ts }}$ & This study \\
\hline YJR13/YCplac111 (myo1D ptor2 ${ }^{\text {ts }}$ ) & $\begin{array}{l}\text { MAT a trp1 ura3 leu2-3 his3 } 1 \text { 1 met- ADE }+ \text { ARG }+ \text { cyh }{ }^{R} \text { myo } 1 \Delta: H I S 5+ \\
\text { YCplac111::tor2-2 } 21^{\text {ts }}\end{array}$ & This study \\
\hline YFR23/pYCplac111 (chs2Dptor2 ${ }^{\text {ts }}$ ) & $\begin{array}{l}\text { MAT a trp1-289 ura3-52 leu2-3, } 112 \text { his3 } 1 \text { ADE }+A R G+\text { cyh }^{R} \text { chs2 } 2: * k a n M X 4, \\
\text { YCplac111::tor2-21 }\end{array}$ & This study \\
\hline YJR13YCplac111pRS316MYO1 (myo1Dptor2 ${ }^{\text {ts }}$ pMYO1) & $\begin{array}{l}\text { MAT a trp1 ura3 leu2-3 his3D1 met- ADE }+ \text { ARG }+ \text { cyh }{ }^{R} \text { myo } 1 \Delta: \text { :HIS5+, } \\
\text { YCplac111::tor2-21 }\end{array}$ & This study \\
\hline 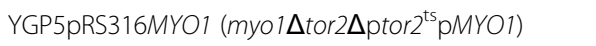 & JK9-3da ade2 tor2::ADE2, myo1D::HIS5+, YCplac111::tor2-21 $1^{\text {ts }}$ pRS316MYO1 & This study \\
\hline
\end{tabular}

removed and quantified using the DC Protein Assay method (Bio-Rad, Hercules, CA).

Whole protein extracts were denatured at $95^{\circ} \mathrm{C}$ for 5 min, separated on 10\% SDS-polyacrylamide gels and transferred to nitrocellulose membrane at 0.37 Amps for $1 \mathrm{~h}$ at $4^{\circ} \mathrm{C}$ in a Mini Trans Blot Cell (Bio-Rad, Hercules, CA). Npr1p was consistently expressed more abundantly in wt cells than in any of the mutant cells. Therefore, the loading volumes were adjusted accordingly. The reason for these differences in Npr1p levels between strains is not known, but it has been speculated that it could be due to differences in the stability of the protein [53]. For analysis of HA-NPR1, membranes were probed with anti-HA rat monoclonal antibody (3 F10, Roche, 1:1000) in blocking solution containing 0.5\% Western Blocking Reagent (Roche) diluted in 1X TBS (Tris Buffered Saline, Sigma Aldrich) at $4^{\circ} \mathrm{C}$ overnight and washed in $1 \mathrm{X}$ TBS/ 0.1\% Tween-20 (TBS/T) (Sigma Aldrich). Membranes were counter-probed with a Horseradish Peroxidase (HRP) conjugated secondary Goat anti-rat IgG antibody (Pierce, 1:5000). For phosphorylated Slt2p (P-Slt2p), membranes were incubated with anti-phospho-p44/42 MAPK rabbit monoclonal antibody (Cell Signaling, $1: 1000$ ) in 5\% BSA (Bovine Serum Albumin, Sigma Aldrich) plus TBS/T buffer at $4^{\circ} \mathrm{C}$ overnight. HRPconjugated secondary antibody was Goat anti-rabbit IgG antibody (Pierce, 1:10000) diluted in blocking solution. For analysis of phosphorylated eukaryotic Initiation 
Factor $\alpha(\mathrm{eIF} 2 \alpha-\mathrm{P})$, the membrane was incubated with anti-phospho-eIF $2 \alpha$ polyclonal antibody (Invitrogen, 1:1000) in blocking solution at $4^{\circ} \mathrm{C}$ overnight. Membranes were stripped and reprobed with a rabbit polyclonal antibody that recognizes both the phosphorylated and unphosphorylated forms of eIF2 $\alpha$ (eIF2 $\alpha$ )(kindly provided by Dr. Thomas E. Dever). HRP-conjugated secondary antibody was Goat anti-rabbit IgG antibody (Pierce, 1:10000) diluted in blocking solution. Membranes were also probed with a mouse monoclonal antibody against Phosphoglycerate kinase (Pgk1p) (Molecular Probes, Invitrogen, 1:500) as a loading control.

Proteins were detected using a chemiluminescent substrate (SuperSignal West Pico, Thermo Scientific), and membranes were exposed to X-ray film, which were then scanned with a Molecular Imager FX Pro Plus (Bio-Rad, Hercules, CA). Digital image intensity was quantified using Quantity One 4.5.2 software (BioRad). Protein bands were quantified according to the ratio of the intensity of the test protein relative to the intensity of its Pgk1p loading control. The obtained values were averaged from duplicate experiments. Quantitative units were expressed as CNT* $\mathrm{mm}^{2}$ or Contour Quantity. This is described as the sum of the intensities of all the pixels within the band boundary multiplied by the area of each pixel (Quantity One, Bio-Rad). Error bars represent the Standard Error of the mean (STDError mean), calculated as the standard deviation (STDEV)/Square root (SQRT) of the count.

\section{Alkaline phosphatase (PPase) treatment of protein extracts}

To generate dephosphorylated proteins, $50 \mu \mathrm{g}$ of whole yeast cell protein extract were incubated with $50 \mathrm{U}(1 \mathrm{U} /$ $\mu \mathrm{g}$ ) of Calf Intestinal Alkaline Phosphatase (CIP or PPase, New England Biolabs) in the presence of 1X CIP buffer (10X NEB 3, New England Biolabs) and 5X Protease Inhibitors cocktail, EDTA Free (50X stock, Roche) for $30 \mathrm{~min}$ at $37^{\circ} \mathrm{C}$. Samples were denatured at $95^{\circ} \mathrm{C}$ for $5 \mathrm{~min}$ and subjected to SDS-PAGE and Western blot analysis.

\section{Viability assay}

Wt, myo1 1 , tor $1 \Delta$, myo $1 \Delta \operatorname{tor} 1 \Delta$, wsc $1 \Delta$ and $m y 01 \Delta$ wsc $1 \Delta$ strains were grown to $\mathrm{OD}_{600}$ between $0.5-0.8 \mathrm{AU}$ at $26^{\circ} \mathrm{C}$ with continuous shaking at $226 \mathrm{rpm}$. $5 \mathrm{uL}$ of serial dilutions ranging from $1 \times 10^{7}-1 \times 10^{2}$ cells $/ \mathrm{mL}$ were spotted onto CSM or selection media agar plates containing 2\% Glucose and 1X Nitrogen base. Plates were incubated at $26^{\circ} \mathrm{C}$ to observe growth after three days of incubation. Strains expressing the temperature sensitive tor $2-21^{t_{s}}$ mutation were streaked on CSM or selection media agar plates, and were incubated at $26^{\circ} \mathrm{C}$ and $37^{\circ} \mathrm{C}$ for 2.5 days.

\section{Additional file}

Additional file 1: Pagán-Mercado, Santiago-Cartagena, Akamine, and Rodríguez-Medina. Assay for viability of yeast strains by growth at $26^{\circ} \mathrm{C}$ and $37^{\circ} \mathrm{C}$ in Leucine-deficient dropout agar medium. Strains wt

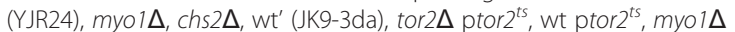
ptor ${ }^{\text {ts }}$, chs $2 \Delta$ ptor2 $2^{\text {ts }}$, tor $2 \Delta$ pTOR2, myo $1 \Delta$ tor $2 \Delta$ ptor $2^{\text {ts }}$ were tested for presence of the ptor ${ }^{\text {ts }}$ plasmid containing the LEU2 marker.

\section{Competing interests}

The authors declare that they have no competing interests.

\section{Authors' contributions}

GP-M performed genetic knockout experiments, Western blotting, growth assays, data analysis and interpretation, and writing sections of the manuscript. ES-C participated in genetic knockout and Western blot experiments of WSC strains and growth assays. PA contributed to the data analysis and interpretation and to the writing and revision of sections of the manuscript. JRR-M as principal investigator, conceived the study, designed experiments, carried out data analysis and interpretation, wrote and revised the manuscript. All authors read and approved the final manuscript.

\section{Acknowledgements}

The authors thank Drs. Brian C. Rymond, Estela Jacinto, Thomas E. Dever, and Michael N. Hall for their kind contribution of essential reagents and yeast strains. We also thank Sahily González-Crespo and Lilliam Villanueva-Alicea for their excellent technical support. This work was supported by a SCORE Award number (5-SC1AI081658-04) from the National Institute of Allergy and Infectious Diseases (NIAID) and National Institute of General Medical Sciences (NIGMS). Partial support for this project was provided through Awards by RCMI (G12RR-03051-26) \& (8 G12-MD007600) and MBRS-RISE (R25GM061838).

Received: 1 December 2011 Accepted: 18 May 2012

Published: 30 May 2012

\section{References}

1. Kamada Y, Jung US, Piotrowski J, Levin DE: The protein kinase C-activated MAP kinase pathway of Saccharomyces cerevisiae mediates a novel aspect of the heat shock response. Genes Dev 1995, 9:1559-1571.

2. Gray JV, Ogas JP, Kamada Y, Stone M, Levin DE, Herskowitz I: A role for the Pkc1 MAP kinase pathway of Saccharomyces cerevisiae in bud emergence and identification of a putative upstream regulator. EMBO J 1997, 16:4924-4937.

3. de Nobel H, Ruiz C, Martin H, Morris W, Brul S, Molina M, Klis FM: Cell wall perturbation in yeast results in dual phosphorylation of the SIt2/Mpk1 MAP kinase and in an Slt2-mediated increase in FKS2-lacZ expression, glucanase resistance and thermotolerance. Microbiology 2000, 146(Pt 9):2121-2132.

4. Rodriguez-Quiñones JF, Irizarry RA, Díaz-Blanco N, Rivera-Molina FE, GarzónGómez D, Rodriguez-Medina JR: Global mRNA expression analysis in myosin II deficient strains of Saccharomyces cerevisiae reveals an impairment of cell integrity functions. BMC Genomics 2008, 9:1-10.

5. Rodriguez-Quiñones JF, Rodríguez-Medina JR: Differential gene expression signatures for cell wall integrity found in chitin synthase II (chs2delta) and myosin II (myo1delta) deficient cytokinesis mutants of Saccharomyces cerevisiae. BMC Res Notes 2009, 2(87):1-7.

6. Rivera-Molina F: Biochemical and genetic analysis of Myosin II function in the trafficking of the Chitin Synthase III catalytic subunit. In PhD Thesis. University of Puerto Rico: Medical Sciences Campus; 2005.

7. VerPlank L, Li R: Cell cycle-regulated trafficking of Chs 2 controls actomyosin ring stability during cytokinesis. Mol Biol Cell 2005, 16(5):2529-2543.

8. Schmidt M, Bowers B, Varma A, Roh DH, Cabib E: In budding yeast, contraction of the actomyosin ring and formation of the primary septum at cytokinesis depend on each other. J Cell Sci 2002, 115:293-302. 
9. Watanabe Y, Takaesu G, Hagiwara M, Irie K, Matsumoto K: Characterization of a serum response factor-like protein in Saccharomycescerevisiae, $\mathrm{Rlm} 1$, which has transcriptional activity regulated by the Mpk1(SIt2) mitogen-activated protein kinase pathway. Mol Cell Biol 1997, 17:2615-2623.

10. Jung US, Levin DE: Genome-wide analysis of gene expression regulated by the yeast cell wall integrity signaling pathway. Mol Microbiol 1999, 34:1049-1057.

11. Garcia R, Bermejo C, Grau C, Perez R, Rodriguez-Pena JM, Francois J, Nombela C, Arroyo J: The global transcriptional response to transient cell wall damage in Saccharomyces cerevisiae and its regulation by the cell integrity signaling pathway. J Biol Chem 2004, 279(15):15183-15195.

12. Lagorce A, Hauser NC, Labourdette D, Rodriguez C, Martin-Yken H, Arroyo J, Hoheisel JD, Francois J: Genome-wide analysis of the response to cell wall mutations in the yeast Saccharomyces cerevisiae. J Biol Chem 2003, 278(22):20345-20357.

13. Heinisch JJ, Lorberg A, Schmitz HP, Jacoby JJ: The protein kinase Cmediated MAP kinase pathway involved in the maintenance of cellular integrity in Saccharomyces cerevisiae. Mol Microbiol 1999, 32:671-680

14. Levin DE: Cell wall integrity signaling in Saccharomyces cerevisiae. Microbiol Mol Biol Rev 2005, 69:262-291.

15. Guo S, Shen X, Yan G, Ma D, Bai X, Li S, Jiang Y: A MAP kinase dependent feedback mechanism controls Rho1 GTPase and actin distribution in yeast. PLoS One 2009, 4(6):e6089.

16. Mazur P, Baginsky W: In vitro activity of 1,3-beta-D-glucan synthase requires the GTP-binding protein Rho1. J Biol Chem 1996, 271(24):14604-14609.

17. Rivera-Ruiz ME, Rodriguez-Quinones JF, Akamine P, Rodriguez-Medina JR: Post-transcriptional regulation in the myo1Delta mutant of Saccharomyces cerevisiae. BMC Genomics 2010, 11:690.

18. Loewith $\mathrm{R}$, Jacinto $\mathrm{E}$, Wullschleger $\mathrm{S}$, Lorberg $\mathrm{A}$, Crespo $\mathrm{J}$, Bonenfant $\mathrm{D}$, Oppliger W, Jence P, Hall MN: Two TOR complexes, only one of which is rapamycin sensitive, have distinct roles in cell growth control. Mol Cell 2002, 10:457-468.

19. Wedaman KP, Reinke A, Anderson S, Yates J 3rd, McCaffery JM, Powers T: Tor kinases are in distinct membrane-associated protein complexes in Saccharomyces cerevisiae. Mol Biol Cell 2003, 14(3):1204-1220.

20. Zheng XF, Florentino D, Chen J, Crabtree GR, Schreiber SL: TOR kinase domains are required for two distinct functions, only one of which is inhibited by rapamycin. Cell 1995, 82:121-130.

21. Helliwell SB, Howald I, Barbet N, Hall MN: TOR2 is part of two related signaling pathways coordinating cell growth in Saccharomyces cerevisiae. Genetics 1998, 148:99-112.

22. Hall MN: The TOR signalling pathway and growth control in yeast Biochem Soc Trans 1996, 24:234-239.

23. Sturgill TW, Cohen A, Diefenbacher M, Trautwein M, Martin DE, Hall MN: TOR1 and TOR2 have distinct locations in live cells. Eukaryot Cell 2008, 7(10):1819-1830.

24. Lavoie $H$, Whiteway $M$ : Increased respiration in the sch9Delta mutant is required for increasing chronological life span but not replicative life span. Eukaryot Cell 2008, 7(7):1127-1135.

25. Kaeberlein M, Powers RW 3rd, Steffen KK, Westman EA, Hu D, Dang N, Kerr EO, Kirkland KT, Fields S, Kennedy BK: Regulation of yeast replicative life span by TOR and Sch9 in response to nutrients. Science 2005, 310:1193-1196.

26. Kaeberlein M, Kapahi P: Aging is RSKy business. Science 2009 326:55-56.

27. Selman C, Tullet JMA, Wieser D, Irvine E, Lingard SJ, Choudhury Al, Claret M, Al-Qassab H, Carmignac D, Ramadani F, Woods A, Robinson ICA, Schuster E, Batterham RL, Kozma SC, Thomas G, Carling D, Okkenhaug K, Thornton JM, Partridge L, Gems D, Withers DJ: Ribosomal protein S6 kinase 1 signaling regulates mammalian life span. Science 2009, 326:140-144.

28. Newton AC: Protein Kinase C: poised to signal. Am J Physiol Endocrinol Metab 2010, 298:395-402.

29. Bickle M, Delley PA, Schmidt A, Hall MN: Cell wall integrity modulates RHO1 activity via the exchange factor ROM2. EMBO J 1998, 17(8):2235-2245

30. Schmidt A, Bickle M, Beck T, Hall MN: The yeast phosphatidylinositol kinase homolog TOR2 activates $\mathrm{RHO} 1$ and $\mathrm{RHO} 2$ via the exchange factor ROM2. Cell 1997, 88(4):531-542.
31. Helliwell SB, Schmidt A, Ohya Y, Hall MN: The Rho1 effector Pkc1, but not Bni1, mediates signalling from Tor2 to the actin cytoskeleton. Curr Biol 1998, 8(22):1211-1214.

32. Rajavel M, Philip B, Buehrer BM, Errede B, Levin DE: Mid2 is a putative sensor for cell integrity signaling in Saccharomyces cerevisiae. Mo/Cell Biol 1999, 19:3969-3976.

33. Verna J, Lodder A, Lee K, Vagts A, Ballester R: A family of genes required for maintenance of cell wall integrity and for the stress response in Saccharomyces cerevisiae. Proc Natl Acad Sci U S A 1997, 94(25):13804-13809.

34. Jacoby JJ, Nilius SM, Heinish JJ: A screen for upstream components of the yeast protein kinase $C$ signal transduction pathway identifies the product of the SLG1 gene. Mol Gen Genet 1998, 258:148-155.

35. Ketela T, Green R, Bussey H: Saccharomyces cerevisiae mid2p is a potential cell wall stress sensor and upstream activator of the PKC1-MPK1 cell integrity pathway. J Bacterio/ 1999, 181:3330-3340.

36. Zu T, Verna J, Ballester R: Mutations in WSC genes for putative stress receptors result in sensitivity to multiple stress conditions and impairment of RIm1-dependent gene expression in Saccharomyces cerevisiae. Mol Genet Genomics 2001, 266(1):142-155.

37. Rodicio R, Heinish JJ: Together we are strong-cell wall integrity sensors in yeasts. Yeast 2010, 27(8):531-540.

38. Reinoso-Martin C, Schuller C, Schuetzer-Muehlbauer M, Kuchler K: The yeast protein kinase $C$ cell integrity pathway mediates tolerance to the antifungal drug caspofungin through activation of Slt2p mitogenactivated protein kinase signaling. Eukaryot Cell 2003, 2:1200-1210.

39. Serrano R, Martin H, Casamayor A, Arino J: Signaling alkaline pH stress in the yeast Saccharomyces cerevisiae through the Wsc1 cell surface sensor and the SIt2 MAPK pathway. J Biol Chem 2006, 281:39785-39795.

40. Straede A, Corran A, Bundy J, Heinisch JJ: The effect of tree oil and antifungal agents on a reporter for yeast cell integrity signalling. Yeast 2007, 24:321-334.

41. Gualtieri T, Ragni E, Mizzi L, Fascio U, Popolo L: The cell wall sensor Wsc1p is involved in reorganization of actin cytoskeleton in response to hypo-osmotic shock in Saccharomyces cerevisiae. Yeast 2004, 21:107-1120.

42. Errede B, Cade RM, Yashar BM, Kamada Y, Levin DE, Irie K, Matsumoto K: Dynamics and organization of MAP kinase signal pathways. J Biol Chem 2000, 275:1511-1519.

43. Martin H, Rodriguez-Pachon JM, Ruiz C, Nombela C, Molina M: Regulatory mechanisms for modulation of signaling through the cell integrity Slt2-mediated pathway in Saccharomyces cerevisiae. J Biol Chem 2000, 275:1511-1519.

44. Claret S, Gatti X, Doignon F, Thoraval D, Crouzet M: The Rgd1p Rho GTPase-Activating Protein and the Mid2p Cell Wall Sensor Are Required at Low pH for Protein Kinase C Pathway Activation and Cell Survival in Saccharomyces cerevisiae. Eukaryot Cell 2005, 4(8):1375-1386.

45. Bermejo C, Garcia R, Straede A, Rodriguez-Pena JM, Nombela C, Heinisch JJ, Arroyo J: Characterization of Sensor-Specific Stress Response by Transcriptional Profiling of wsc1 and mid2 deletion strains and chimeric sensors in Saccharomyces cerevisiae. OMICS 2010, 14(6):679-688.

46. Vilella F, Herrero E, Torres J, de la Torre-Ruiz MA: Pkc1 and Upstream Elements of the Cell Integrity Pathway in Saccharomyces cerevisiae, Rom2 and Mtl1, Are Required for Cellular Responses to Oxidative Stress. J Biol Chem 2005, 280(10):9149-9159.

47. Petkova M, Pujol-Carrion N, Arroyo J, García-Cantalejo J, de la Torre-Ruiz MA: Mtl1 is required to activate general stress response through Tor1 and Ras 2 inhibition under conditions of glucose starvation and oxidative stress. J Biol Chem 2010, 285(25):19521-19531.

48. Philip B, Levin DE: Wsc1 and Mid2 are cell surface sensors for cell wall integrity signaling that act through Rom2, a guanine nucleotide exchange factor for Rho1. Mol Cell Biol 2001, 21:271-280.

49. Tarassov K, Messier V, Landry CR, Radinovic S, Serna Molina MM, Shames I, Malitskaya Y, Vogel J, Bussey H, Michnick SW: An in vivo map of the yeast protein interactome. Science 2008, 320(5882):1465-1470.

50. Jacinto E: Phosphatase targets in TOR signaling. Methods Mol Biol 2007, 365:323-333.

51. Schmidt A, Beck T, Koller A, Kunz J, Hall MN: The TOR nutrient signaling pathway phosphorylates NPR1 and inhibits turnover of the tryptophan permease. EMBO J 1998, 17:6924-6931. 
52. Bonenfant $\mathrm{D}$ : Mass spectrometric analysis of the rapamycin-sensitive phosphorylation sites of the yeast protein kinase NPR1. In Biochemical Department. Biozentrum: University of Basel; 2003.

53. Jacinto E, Guo B, Arndt KT, Schmelzle T, Hall MN: TIP41 interacts with TAP42and negatively regulates the TOR signaling pathway. Mol Cell 2001, 8(5):1017-1026.

54. Ito H, Fukuda Y, Muruta K, Kimura A: Transformation of intact yeast cells treated with alkaline cations. J Bacteriol 1983, 153(1):163-168.

55. Silverman SJ, Sburlati A, Slater ML, Cabib E: Chitin synthase 2 is essential for septum formation and cell division in Saccharomyces cerevisiae. Proc Natl Acad Sci USA 1988, 85:4735-4739.

56. Ram A, Kapteyn JC, Montijn RC, Caro LHP, Douwes JE, Baginsky W, Mazur P, Van den Ende $\mathrm{H}$, Klis FM: Loss of the plasma membrane-bound protein Gas1p in Saccharomyces cerevisiae results in the release of B-1,3-glucan into the medium and induces a compensation mechanism to ensure cell wall integrity. J Bacteriol 1998, 180:1418-1424.

57. Jiang $Y$, Broach JR: Tor proteins and protein phosphatase $2 A$ reciprocally regulate Tap42 in controlling cell growth in yeast. EMBO J 1999, 18(No.10):2782-2792.

58. Di Como CJ, Arndt KT: Nutrients, via the TOR proteins, stimulate the association of TAP42 with type 2a phosphatases. Genes Dev 1996, 10:1904-1916.

59. Torres J, Di Como CJ, Herrero E, De la Torre-Ruiz MA: Regulation of the cell integrity pathway by Rapamycin-sensitive TOR function in budding yeast. J Biol Chem 2002, 277(no.45):43495-43504.

60. Barbet NC, Schneider U, Helliwell SB, Stansfield I, Tuite MF, Hall MN: TOR controls translation initiation and early $\mathrm{G} 1$ progression in yeast. Mol Biol Cell 1996, 7(1):25-42

61. Schmidt A, Kunz J, Hall MN: TOR2 is required for organization of the actin cytoskeleton in yeast. Proc Natl Acad Sci U S A 1996, 93(24):13780-13785.

62. De la Torre-Ruiz MA, Torres J, Ariñol J, Herrero E: Sit4 is required for proper modulation of the biological functions mediated by PKC1 and the Cell Integrity Pathway in Saccharomyces cerevisiae. J Biol Chem 2002, 277(36):33468-33476.

63. Cherkasova VA, Hinnebush Alan G: Translational control by TOR and TAP42 through dephosphorylation of elF2 alpha kinase GCN2. Genes Dev 2003, 17:859-872.

64. Grenson M: Study of the positive control of the general amino acid permease and other ammonia-sensitive uptake systems by the product of the NPR1 gene in the yeast Saccharomyces cerevisiae. Eur J Biochem 1983, 133:141-144

65. Vandenbol M, Jauniaux JC, Vissers S, Grenson M: Isolation of the NPR1 gene responsible for the reactivation ammonia-sensitive amino acid permeases in Saccharomyces cerevisiae. Eur I Biochem 1987, 164:607-612.

66. Fang X, Luo J, Nishihama R, Wloka C, Dravis C, Travaglia M, Iwase M, Vallen $\mathrm{EA}, \mathrm{Bi}$ E: Biphasic targeting and cleavage furrow ingression directed by the tail of a myosin II. J Cell Biol 2010, 191(7):1333-1350.

67. Lord M, Laves E, Pollard TD: Cytokinesis depends on the motor domains of myosin-ll in fission yeast but not in budding yeast. Mol Biol Cell 2005, 16(11):5346-5355.

68. Lister IM, Tolliday NJ, Li R: Characterization of the minimum domain required for targeting budding yeast myosin II to the site of cell division. BMC Biol 2006, 4:19.

69. Cardon CM, Beck T, Hall MN, Rutter J: PAS kinase promotes cell survival and growth through activation of Rho1. Sci Signal 2012, 5(209):ra9.

doi:10.1186/1471-2121-13-13

Cite this article as: Pagán-Mercado et al:: Functional and genetic interactions of TOR in the budding yeast Saccharomyces cerevisiae with myosin type II-deficiency (myo14). BMC Cell Biology 2012 13:13.

\section{Submit your next manuscript to BioMed Central and take full advantage of:}

- Convenient online submission

- Thorough peer review

- No space constraints or color figure charges

- Immediate publication on acceptance

- Inclusion in PubMed, CAS, Scopus and Google Scholar

- Research which is freely available for redistribution

Submit your manuscript at www.biomedcentral.com/submit
Ciomed Central 